Provided for non-commercial research and education use. Not for reproduction, distribution or commercial use.

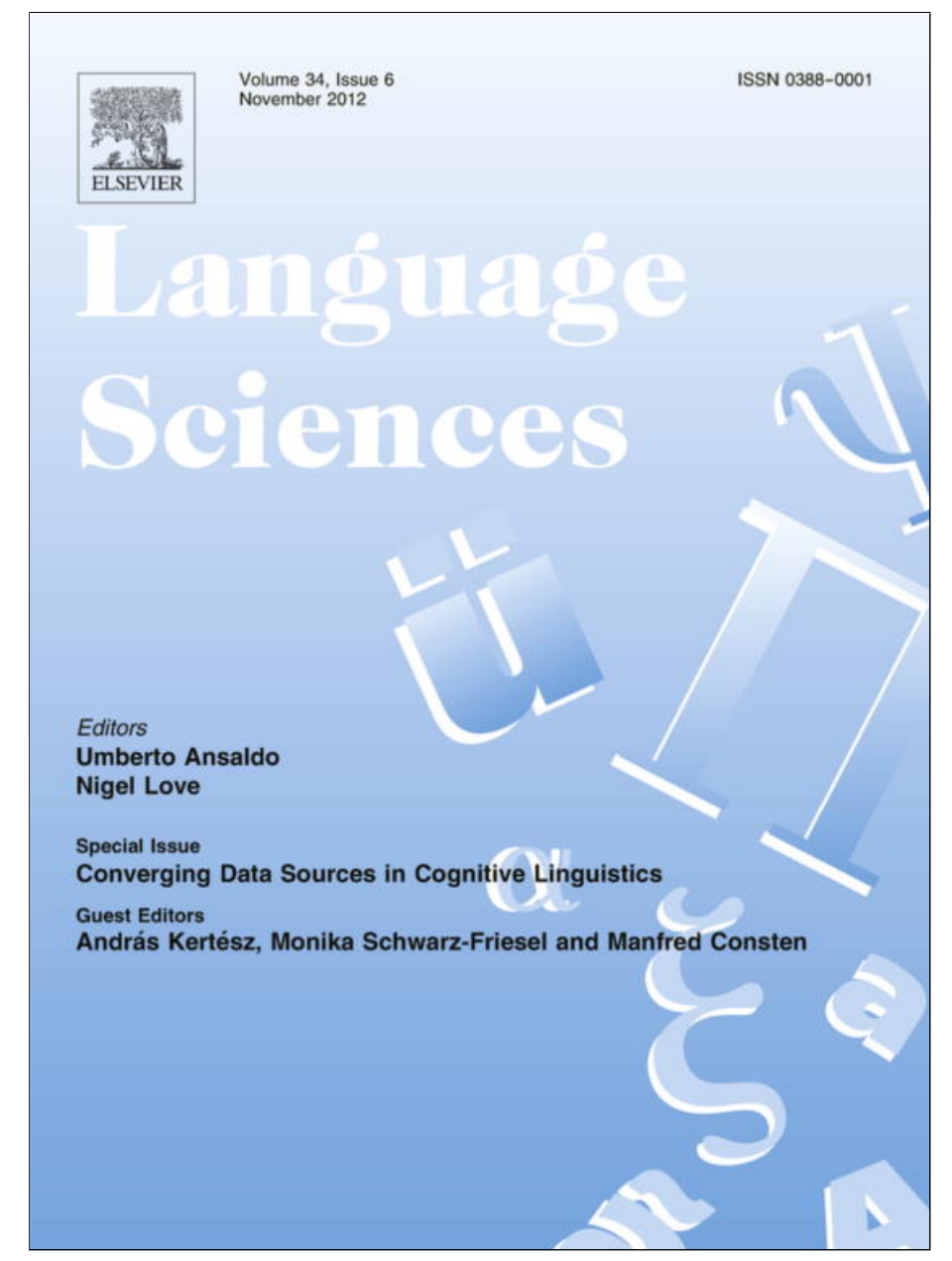

This article appeared in a journal published by Elsevier. The attached copy is furnished to the author for internal non-commercial research and education use, including for instruction at the authors institution and sharing with colleagues.

Other uses, including reproduction and distribution, or selling or licensing copies, or posting to personal, institutional or third party websites are prohibited.

In most cases authors are permitted to post their version of the article (e.g. in Word or Tex form) to their personal website or institutional repository. Authors requiring further information regarding Elsevier's archiving and manuscript policies are encouraged to visit:

http://www.elsevier.com/copyright 


\title{
How does 'cognition' matter to the analysis of talk-in-interaction?
}

\author{
Arnulf Deppermann \\ Institute for the German Language, P.O. Box 101621, D-68161 Mannheim, Germany
}

\section{A R T I C L E I N F O}

\section{Article history:}

Available online 25 June 2012

\section{Keywords:}

Conversation analysis

Discursive psychology

Cognition

Mentalism

Understanding in interaction

\begin{abstract}
A B S T R A C T
Conversation Analysis (CA) and Discursive Psychology (DP) reject the view that assumptions about cognitive processes should be used to account for discursive phenomena. Instead, cognitive issues are respecified as discursive phenomena. Discursive psychologists do this by studying discursive practices of talking about mental phenomena and using mental predicates. This approach is exemplified by a study of the use of constructions with German verstehen ('to understand') in conversation. Some conversation analysts take another approach, namely, inquiring into how participants display mental states in talk-in-interaction. This is exemplified by a study of how grammatical constructions are used to display different types of inferences drawn from a partner's prior turn. It will be argued that the constructivist, antiessentialist stance which CA and DP take with regard to cognition is a prosperous line of research, which has much in its favor from a methodological point of view. However, it can be shown that tacit assumptions about cognitive processes are still inevitable when doing CA and DP. As a conclusion, the paper pleads for an enhanced awareness of how cognitive processes come into play when analysing talk-in-interaction and it advocates the integration of a more explicit cognitive perspective into research on talk-in-interaction.
\end{abstract}

(c) 2012 Elsevier Ltd. All rights reserved.

\section{Before and beyond conversation analysis: cognition as an explanatory resource}

For laymen as well as for cognitive psychologists, it is commonplace to say that cognition explains actions in interaction. In fact, in the context of cognitive science it seems hard to imagine that human action can occur without cognition (Graesser, 2006). Auditory and visual perception are seen as a precondition for situated action, which is sensitive to its local surroundings; intentions (Gibbs, 1999) and plans (Grosz and Sidner, 1990) are judged to be the motivations and guidelines for actions; shared knowledge is seen as a prerequisite and as the outcome of conversational interaction (Pickering and Garrod, 2004; Clark, 1996), and inferences are regarded as being constitutive of understanding (Kintsch, 1998; Hobbs, 2004). According to this conception, language is "a window onto cognition" (see the journal "Language and Cognition"). Language is an epiphenomenon depending on prior cognitive states, which motivate linguistic action and define its meaning. Methodologically, the cognitivist enterprise rests on experimentation, computer simulation, and verbal reports. While the latter (like questionnaires and thinking-aloud protocols) are taken at face value as representations of cognitive processes within the respondent, simulation provides generative accounts of how declarative and procedural knowledge produces actions, and experiments allow for various ways to test how different states of knowledge inform action, how inferences depend on input stimuli, etc. Since naturally occurring interaction is hardly adaptable to the standards of experimental methodology, it has only very rarely been studied in its own right by cognitivists - the studies by Herbert Clark (e.g., 1992, 1997) being a notable example. However, most cognitivists would claim that their results are also applicable to everyday conversation, and, what matters even more in our context, that the overarching model of cognition as the indispensable prerequisite for (inter-)action and thus as the most relevant source for its explanation is without any reasonable alternative.

E-mail address: deppermann@ids-mannheim.de 


\section{Data and methods in CA and DP}

\subsection{Data}

Since Sacks' early lectures, the project of CA was a natural sociology, which is interested in the construction of social order by observable, everyday activities (Sacks, 1992, 1984). Primary data for CA are naturally occurring social interactions, which are audio- or video-taped. They are transcribed according to conventions which aim at preserving the interactionally relevant properties of spoken language and interaction in the written record (see Deppermann and Schütte, 2008). Data may come from everyday conversation, institutional encounters, or from some kind of mediated interaction. If CA uses data from settings arranged for scientific purposes such as interviews, these data are researched in terms of their logic of constitution, i.e., regarding the interaction between the researcher and the researched (Drew et al., 2006; Schaeffer and Maynard, 2006), but not - as usually in psychology and social science - as devices for gathering factual information from the respondent. In its beginnings, DP worked a lot with media-texts; meanwhile, it uses data very much alike to those used in CA.

In contrast to Cognitive Linguistics, both CA and DP reject the use of invented examples. In fact, most of CA's findings would never have been made, if research had to rely on intuition, because the phenomena could either not have been imagined or they would have been rejected as not well-formed (Heritage, 1984b, p. 238).

\subsection{Methods for analysis}

Both CA and DP use two basic methodologies of analysis: The detailed sequential analysis of single cases and the analysis of collections of a practice. The sequential analysis sets out to show how an interactional sequence is organized according to the maxim of "order at all points" (Sacks, 1984). This implies that each phenomenon in the sequence is methodically produced as a context-sensitive contribution to the local interactional process of sense-making and that it is being responded to as such. Most basic for this approach is the notion of 'sequentiality', i.e., each action has to be understood in terms of how it is tailored to its sequential context both in its form and in its function. 'Sequential analysis' crucially also implies to ground analysis in how the participants themselves respond to and interpret interactional phenomena in their subsequent reactions. Sequential analysis is in stark contrast to Cognitive Linguistics, which never deals with data from spoken interaction, but overwhelmingly analyses isolated sentences disregarding their textual context (if they have one, being sentences invented for purposes of linguistic demonstration) and ignoring their import as social actions.

Sequential analysis combines with the analysis of collections in the pursuit of identifying interactional practices. Practices are methodically organized ways of producing and reacting to interactional phenomena, which are characterized by formal properties (e.g., linguistic features) and which are used for specific functions (e.g., actions) in specific sequential environments. A collection consists of instances of a practice which were found in a corpus. A collection usually includes not only typical cases, but also

- boundary cases, whose status may be unclear or which border on other practices,

- deviant cases, which can be especially valuable, because they might reveal properties of the practice (in particular, normative expectations associated with it), which remain unnoticed in the typical case,

- variants, which depend on specific contextual conditions.

The analyst's task is to refine the collection and the description of the practice in such a way that s/he succeeds in giving an account for all instances of the practice encountered in terms of its formal, functional and sequence-organizational features.

In contrast to corpus linguistics, CA and DP usually do not rely on quantitative measures. Their aim is not to correlate linguistic and other discourse phenomena with discourse-external factors, such as social and psychological properties of the participants. CA and DP require the analyst to show how each instance analyzed is to be understood as a contextually sensitive accomplishment in its own sequential environment (“unique adequacy requirement”; Psathas, 1995, p. 17). CA and DP demand that the immediate sequential and often also larger interactional contexts are to be taken into account in the way they can be shown to be demonstrably relevant in the participants's actions. While most researchers are utterly sceptical about combining CA with quantitative methods (see Schegloff, 1993), some use CA for developing inductive, data-driven codes and for the qualitative explication of quantitative patterns (Heritage, 1999).

\section{The antimentalist stance in CA and DP}

When dealing with CA's stance towards cognition, it has to be kept in mind that it is a sociological approach. Although matters of cognition, such as understanding or inference, were present in the agenda of CA already from the very beginning (cf. Sacks, 1985, 1992), its approach is not cognitivist, but pragmatic and observational. So, the question is not how cognition motivates action and how the researcher can methodically gain insight into the workings of the mind. Instead, what interests CA is at what point cognitive ascriptions, such as to understand, to know, or to feel something, become relevant in social 
interaction for the participants and how they come to be displayed "hearably" in the interactional conduct by methodical ways of acting.

DP started as a constructivist critique of mainstream social and cognitive psychology (cf. Potter and Wetherell, 1987; Edwards and Potter, 1992; Edwards, 1997). Building on CA, but also on Ethnomethodology (Coulter, 1989) and the philosophy of language of the late Wittgenstein (1953), DP objects to the reification of mental constructs as objective causes of behavior. Instead of treating cognitive terms as an analyst's resource to explain action by recourse to a seemingly more powerful invisible mental world, it aims at an analysis of how psychological issues crop up in people's talk, i.e., how they are constructed as a resource for performing social actions.

There are several objections which are raised by CA and DP against cognitivist approaches and the use of mental assumptions as an analytic tool (see also Potter and te Molder, 2006):

- Abstractness of cognitive models: Cognitive models, such as scripts or plans for discourse, abstract away from contingent situational details, which are inevitably pertinent and ever changing in everyday interaction. Therefore they only manage to explain and predict actions in a restricted and idealized universe of discourse without being able to account for the local sensitivity of interactional conduct in the real world (cf. Pomerantz, 1990/91; Suchman, 1987).

- Insufficient quality of data studied: Cognitivists do not work with audio-/video-recordings and transcripts, which capture all details of talk-in-interaction precisely, including all phenomena which might not have been expected by the researcher in advance. If cognitive researchers ever deal with data from social interaction, they work with idealized and summarized representations in the form of sample codings, glosses of interactional scenes, representations of written instructions instead of recordings of what was really said to the subjects under study, transcripts cleaned up according to the standards of orthography, and recollections from interviews, which are taken to represent what happened in an interaction. All of these data dismiss details of the interaction which are judged to be unimportant with respect to the research question and they are in many ways subject to selective and interpretive choices by respondents and/or researchers (Bergmann, 1985; Cicourel, 1970).

- Methodological Individualism: In cognitive accounts, the sources for the constitution of action are located in the mind of the individual. The interactional partner comes into play only as a provider of input to be processed and by way of (meta)representations, i.e., by goals regarding the addressee, assumptions about what is shared knowledge and by mental models comprising psychological, social, etc. properties which are ascribed to the partner. From this perspective, interaction is seen as a chain of contributions from individual actors. By reducing interactional reality to individual (meta-)representations, the dialogical nature of interaction as a realm with its own order of phenomena and rules, which cannot be reduced to productions of individuals, ceases to exist (Linell, 2009). Pervasive interactional phenomena like repair, collaborative sentence production, and the dialogical negotiation and reinterpretation of meaning are likely to be missed by an individualistic perspective on interaction. Interactional orders of conduct like social preferences for response types and trajectories of conflict talk cannot be accounted for by recourse to individual representations.

- Circularity of cognitive explanation: The most basic objection against a cognitive approach raised is against its ontological validity. In his Philosophische Untersuchungen, Wittgenstein (1953) argued that terms like pain and thinking designating private experiences and mental processes do not function on behalf of their referential properties. There neither needs to be some definite experiential referent (as in the case of think) nor is there any chance for securing a shared referential interpretation, because mental states and processes do not lend themselves to (direct) observation. Similar to Ryle's (1949) methodological behaviorism, Wittgenstein drew the conclusion that the meaning of mental terms is not to be located in mental processes, but in discursive conventions of interpreting overt, i.e., publicly observable behavior as an expression of mental states. Thus, it is the use of the mental terms themselves within a social "language game", which accounts for their meaning, and not the existence and nature of the cognitive phenomena, which mental terms purport to refer to. A related, even more radical view is taken by Quine (1960) who accuses cognitive accounts of plain circularity: If one explains, e.g., the meaning of words by mental representations, one can do so solely by recourse to the properties of the use of the words themselves. That is, properties of the discourse are projected onto the individual's mind, which then is (mis)taken as the motivating, explanatory, and meaning-providing source of linguistic practice (see also Potter, 2006). However, there is neither independent evidence for the workings of cognition apart from the phenomena they are invoked to explain nor is it clear how mental representations themselves should be interpreted, except by using the very language they should explain, thus leading to the need for an indefinite regress. Therefore, Quine concludes, the recourse to cognition as an explanation is a circular and redundant reification. Very similar stances against cognitive explanation have been taken by ethnomethodologists like Coulter $(1989,2006)$, who claims: "The logic is implicit in the practices, not a mental addendum to them." (Coulter, 2006, p. 91).

\section{Cognition as a research topic of CA and DP}

Whereas Sacks was already interested in cognitive issues like 'understanding' from a discursive point of view, they ceased to be an object of study in CA until the early 1990s (see, e.g., Heritage, 1990/91; Pomerantz, 1990/91). Only in recent years, cognitive issues have become a major topic in CA, especially with a focus on the relevance and the display of knowledge in interaction (Sidnell, 2005; Heritage, 2006; Heritage and Raymond, 2005). CA-studies turned to cognitive issues on a very phenomenon-oriented basis, i.e., dealing with specific interactional activities, practices and problems having to do with 
cognition in interaction, but they did not aim at a broader epistemological discussion of the issue of how cognition relates to interaction. In contrast, this is one of the main objectives of DP, which set out to respecify cognitive phenomena as phenomena of discourse (Edwards, 1997; Potter and te Molder, 2006; Edwards and Potter, 1998, 2006). Over the years, DP has increasingly moved from a discourse-analytic method dealing with texts to a CA-like approach of studying psychological phenomena as a topic of conversational and institutional interaction (cf. Wooffitt, 2005). The volume edited by te Molder and Potter (2006) shows and discusses the commonalities and differences in the approaches to cognition in conversation taken by CA and DP. The most relevant commonalities, which all are in contrast to cognitive approaches, are (see also Edwards, 1997; Potter and te Molder, 2006):

- Ontological respecification: Cognitive phenomena are studied as they are observably oriented to by participants in the interaction and not as abstract phenomena existing in a mental world of the individual participants. Thus they are neither regarded as determinants of discursive action nor as its outcome. The focus instead is on socially organized practices of talking about and displaying cognitive states and processes.

- Discursive topic vs. analyst's resource: The analyst does not take recourse to cognitive ascriptions in order to explain actions in interaction, but asks how participants themselves use the recourse to cognitive phenomena as a discursive topic. Hence, questions addressed are: When do cognitive issues become relevant in interaction? How are they made relevant and established as facts?

- Pragmatic vs. representational view of the relationship between cognition and discourse: Especially DP takes a strictly constructivist approach to talking about mental phenomena: It does not treat them as discursive representations or expressions of an underlying mental reality, but as social action (see also Potter et al., 1993; Edwards and Potter, 2006). Thus, "mentalese" is not taken to be a referential window onto cognitive processes and factual reality: Using some mental term for self-reference or claiming to be in some mental state does not necessarily imply that the speaker is in this state. Mentalese is shown to be rather a rhetorical device which is systematically deployed to accomplish actions such as justifying, blaming, complaining, and distancing oneself from stake-ascriptions. For example, Potter (1997) shows how I dunno is used to indicate that the speaker has no particular self-serving interest in making a claim, although s/he might be suspected to. Edwards (1997, pp. 114-141) deals with formulations of common ground, arguing that they are used as rhetorical devices, e.g., to assert positions as being uncontroversial in the face of (possible) objections and disagreement.

- Functional vs. intentional view of actions: In cognitive accounts, behavior is categorized as action according to the speaker's intentions (e.g., Searle, 1983). CA and DP, however, hold that the categorization of behavior as action is a social matter. Earlier work in DP turned to social conventions and practices taken to be known by the analyst as part of his/her cultural knowledge as the source for assigning meaning to actions (see Edwards and Potter, 1992). Thus, actions are constituted as such by reference to social rules (like in early speech act theory, see Austin, 1962; Searle, 1969) and not by reference to individual cognition. DP, however, has increasingly joined the method of sequential analysis used by CA. For CA, it is not individual actions which are the object of study, but action sequences (see Atkinson and Heritage, 1984; Schegloff, 1992, 1995). Which action is performed by some behavior has to be analyzed with respect to what it is doing in a given sequential context to which it is tailored. What matters even more in epistemological terms, is that the meaning of any conversational behavior is object to subsequent collaborative interpretation and negotiation. Thus, actions as such are not defined by individual cognition, but they are located on the interactional plane, and it is the discursive function as attested by observable interactional consequences, which lays the foundation for analytic claims about action properties, and not the ascription of speaker intentions. In terms of speech act theory, illocutionary properties are not separated from perlocutionary ones, but the latter are used to identify the former, because their social reality has to be proven by the interactional processes they help to engender.

In CA and DP, 'cognition' thus is relocated ontologically: It is not seen as an abstract psychological feature, residing inside the mind of an individual, but it is treated as a discursive phenomenon, which is publicly displayed and collaboratively oriented to by the parties to a conversation. Turning to the study of cognition in interaction, we can distinguish three different kinds of phenomena:

- The use of mental predicates (like I dunno, think, verstehen 'understand', see below): This line of research is an empirical realization of Wittgenstein's approach to cognition, which aims at elucidating the meaning and the relevance of 'cognition' for a community of practice by studying how terms designating mental processes and states are used. This approach, which is taken by DP, is strictly constructivist, being uninterested in and agnostic (or, rather, sceptical) about the existence of cognitive phenomena (cf. Edwards and Potter, 2006). Instead, research focuses on the overt and explicit, ascriptive use of cognitive terms as means of performing rhetorically designed actions.

- The interactional practices of displaying, claiming, and ascribing cognitive phenomena: Participants in interaction can orient to cognitive phenomena in still other ways than making them an explicit topic of talk by using mental predicates. Sacks (1992/2, $141 \mathrm{ff}$.) already distinguished "claiming understanding” (via explicit self-ascriptions like I know what you mean) from "demonstrating understanding" by performing actions which give evidence of understanding by drawing a relevant inference. Researchers from CA have increasingly become interested in practices by which participants display, claim, and ascribe cognitive states to themselves and others. An important area of research is epistemics, i.e., the display of the acquisition, ownership, and superiority of knowledge. For example, Heritage (1984a,b, 2006) dealt with oh as a 
change-of-state token which displays that the speaker has gained a revised understanding, which is contrary to prior expectations; Heritage and Raymond (2005) deal with how speakers display epistemic authority, superiority and independent access regarding matters assessed in the talk. Other issues concern claims to and ascriptions of credibility, certainty, and expertise regarding factual accounts (Edwards and Potter, 1992; Deppermann, 1997) and advice-giving (Sidnell, 2005), and the display of scepticism (Wolff and Müller, 1997). These studies focus on routine, conventional ways of orienting to epistemic, or more broadly, cognitive issues in interaction. They do not assume that displaying some cognitive phenomenon necessarily amounts to really being in the respective cognitive state nor do they suggest that the researched discursive practices are results or symptomatic by-products of some (prior) cognitive process. Such a perspective, however, is pursued in Drew's studies on planning in conversation (Drew, 1995) and on displays of confusion (Drew, 2006) and in Heritage's paper on strategy in interaction (Heritage, 1990/91). These papers point out methodological difficulties and requirements which have to be met when trying to link conversational data to cognitive processes of the participants. Although they treat the issue with caution, they are inclined to adopt the view that some conversational phenomena lend themselves to an interpretation in terms of underlying cognitive processes, thus giving evidence of how mental states motivate discursive phenomena. Consequently, these studies seem to suggest that there may be a bridge to be built between the undertakings of CA and some of the issues of Cognitive Science. This attempt, however, is strictly rejected by DP (see Potter, 2006 on Drew $(1995,2006))$ because of the methodological consideration that it is in principle not possible to infer the factual existence of some cognitive process from discourse data.

In sum, CA and DP have a common interest in participants' conventional and situated practices of orienting to cognition in interaction and in the kind of interactional work they do in their sequential contexts. 'Cognition' is a major topic of current research in CA and DP in terms of being a socially organized field of phenomena, which matter in manifold ways for discursive action. However, while DP favors a more rigid constructivist approach, which denies the possibility to reach for cognitive states prior or beyond discursive action, some CA-researchers seem to assume that cognition plays an irreducible role in the constitution of interaction in terms of knowledge and understanding. The latter argue that cognition needs to be incorporated into CA's research agenda and into the analysis of interactional practices. Interestingly, another possible approach to investigating cognition in interaction has been taken neither by CA nor DP yet: The way how cognition is conceived of in terms of descriptive practices (e.g., by the use of metaphors and metonyms) sometimes figured peripherally in studies, but since CA's and DP's focus is not on content, but rather on function, the issue of how cognition is conceptualized in talk has not become a topic in its own right. This is in stark contrast to Cognitive Linguistics, where linguistically encoded, cultural models of cognition have become a major topic of research since the very beginning of Cognitive Linguistics starting with Lakoff and Johnson (1980). Indeed, a major critique of Edwards (1997) raised against Cognitive Linguistics (e.g., Lakoff, 1987) is that it confuses features of linguistic conceptualization with cognitive realities of representation and experience and that it altogether neglects the pragmatic contexts in which specific formats of description are used and by which they are functionally motivated.

\section{Understanding in interaction: examples for the study of 'cognition' within a CA-framework}

This section takes 'understanding' as an example to elucidate in more concrete detail the different approaches by CA and DA to cognitive phenomena outlined in Section 4. It builds on findings from a research project at the Institute for the German Language (Mannheim/Germany) on understanding in interaction. Taking a CA-inspired approach with specific emphasis on linguistic issues along the methodological lines of 'Interactional Linguistics' (Barth-Weingarten, 2008; Couper-Kuhlen and Selting, 2001), the project deals with verbal and communicative displays of understanding in talk-in-interaction. It seeks to identify practices participants use to display how they understand their interlocutors' contributions, how they assume to have been understood by their interlocutors and how they intend to be understood by their interlocutors. The research agenda includes the description of linguistic constructions and of interactive, sequential forms of organization of practices of displaying understanding and investigates their interactional habitats. In addition to their functions for understanding in talk-in-interaction, like DP, Interactional Linguistics aims at identifying rhetorical functions and pragmatic tasks that go beyond the management of understanding, such as arguing, persuading, criticizing, and negotiating relationships between participants.

When dealing with 'understanding' from a CA-point of view, the area of interest is respecified with regard to cognitive approaches in several respects (Deppermann, 2008; Deppermann and Schmitt, 2009):

- We do not aim at analyzing the mental processes which go on in the brain when understanding takes place, but we are interested in the linguistic and communicative practices by which understanding is displayed and ascribed in interaction.

- We do not focus on private mental processes, but on observable phenomena in the interaction, which are treated by participants as claims to and evidence of understanding and by which tasks and problems of understanding are dealt with.

- The analysis does not rely on a normative view of what is to count as correct (more profound, etc.) understanding and as misunderstanding, but we want to know how participants themselves orient to issues of understanding in talk (including whether, when, how, for whom, to which degree, by which criteria, etc. issues of correctness come into play).

- We do not restrict 'understanding' to the common linguistic objects of reference, propositional content, illocutionary acts, and implicatures, but we attend to all problems of understanding which emerge in interaction for the participants. These, however, may range well beyond the classical topics. For example, the question whether another speaker should take the 
turn after the end of a turn-constructional unit or whether the current speaker is to be understood as projecting turn-continuation may as well be a task for understanding as is to judge whether a person is available for talk for someone who is approaching him/her.

- Whenever understanding is made a topic of talk, we do not presuppose that (only) understanding is at issue for the participants. Rather, we are interested in the practical and rhetorical uses of displays of and talk about understanding for the organization of social relationships, collective actions, and the opportunities for individual participation.

The two main approaches to cognitive phenomena taken by CA and DP (cf. Section 4) will be exemplified with regard to 'understanding' in interaction:

- The use of mental predicates in interaction is exemplified by two constructions with the German verb verstehen ('to understand').

- Practices of displaying cognitive processes are exemplified by two different practices of performing an action which is (linguistically) framed as being an inference from a partner's prior turn

\subsection{Verstehen-constructions}

Three-hundred instances of verstehen in naturally occurring interactions were randomly collected from data from the archive of spoken German at the Institute for the German Language (IDS Mannheim: www.agd.ids-mannheim.de). They cover a wide range of types of interaction: institutional talk (counselling, mediation, doctor-patient interaction, psychiatric intakeinterviews, seminars in higher education, research interviews), mediated talk (talk shows, phone-ins, political debates), and leisure-time interactions among adolescents. As we expected that the semantics and the pragmatic uses of lexical items depends on the grammatical constructions in which they are used, we decided to compare the two most pervasive constructions with verstehen in the corpus: [(NP) nicht verstehen (können) (COMP)] (negative construction) and [verstehen sie/verstehst $(d u) / v e r s t e h t ~ i h r ?]$ ('do you understand?'). ${ }^{1}$ These two constructions do not only occur frequently enough for a systematic comparison, they also differ in many syntactic respects. Because of this, they are apt candidates for determining whether and how different constructional contexts entail semantic and pragmatic differences and which role the lexical item verstehen as such plays for situated uses and meanings.

5.1.1. The negative construction [(NP) nicht verstehen (können) (COMP)]

Extract \#1 shows a typical example of the negative construction:

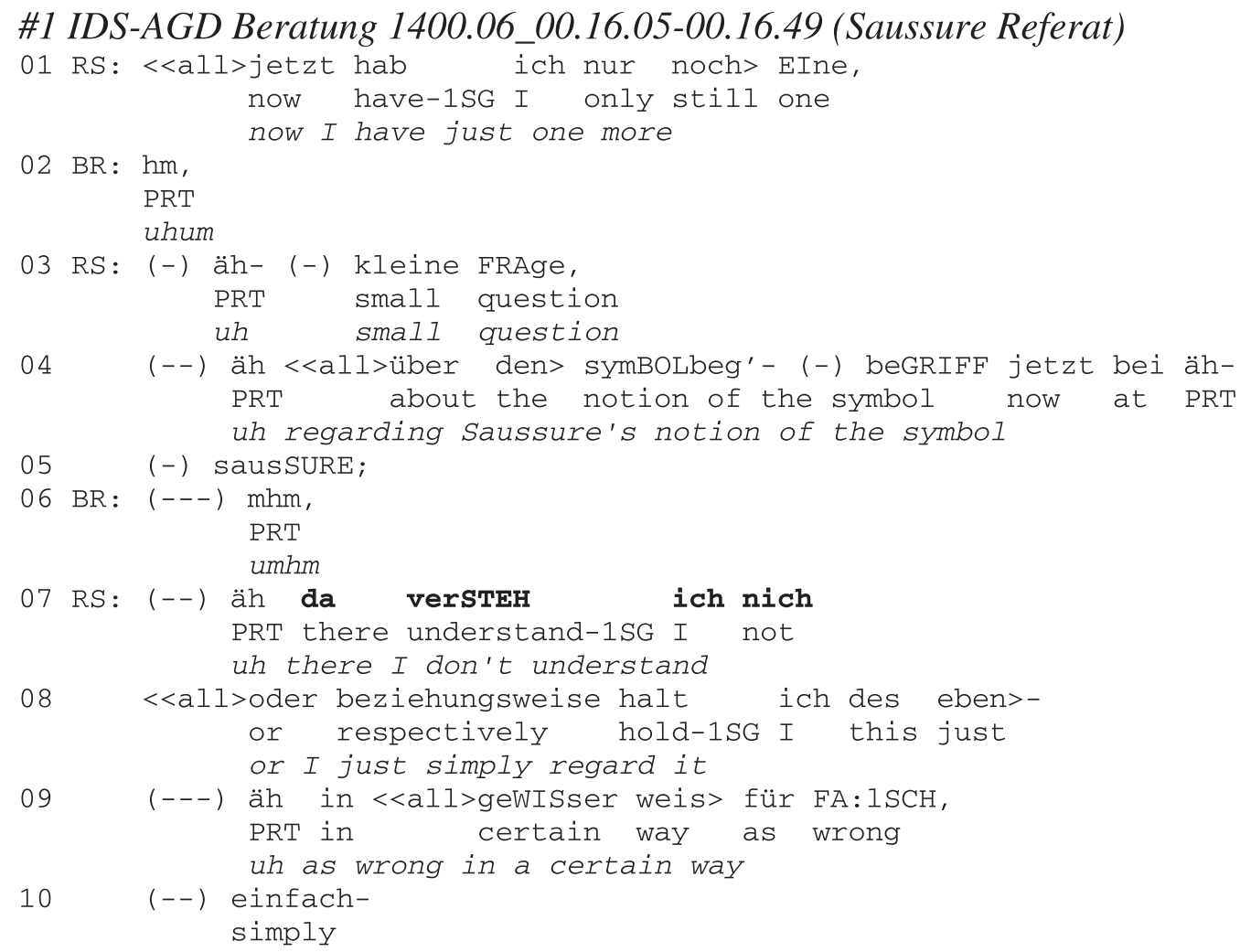

\footnotetext{
${ }^{1}$ See Deppermann (2011a) for a more detailed account of the results of the study and for a discussion with respect to the theoretical framework of construction grammar.
} 


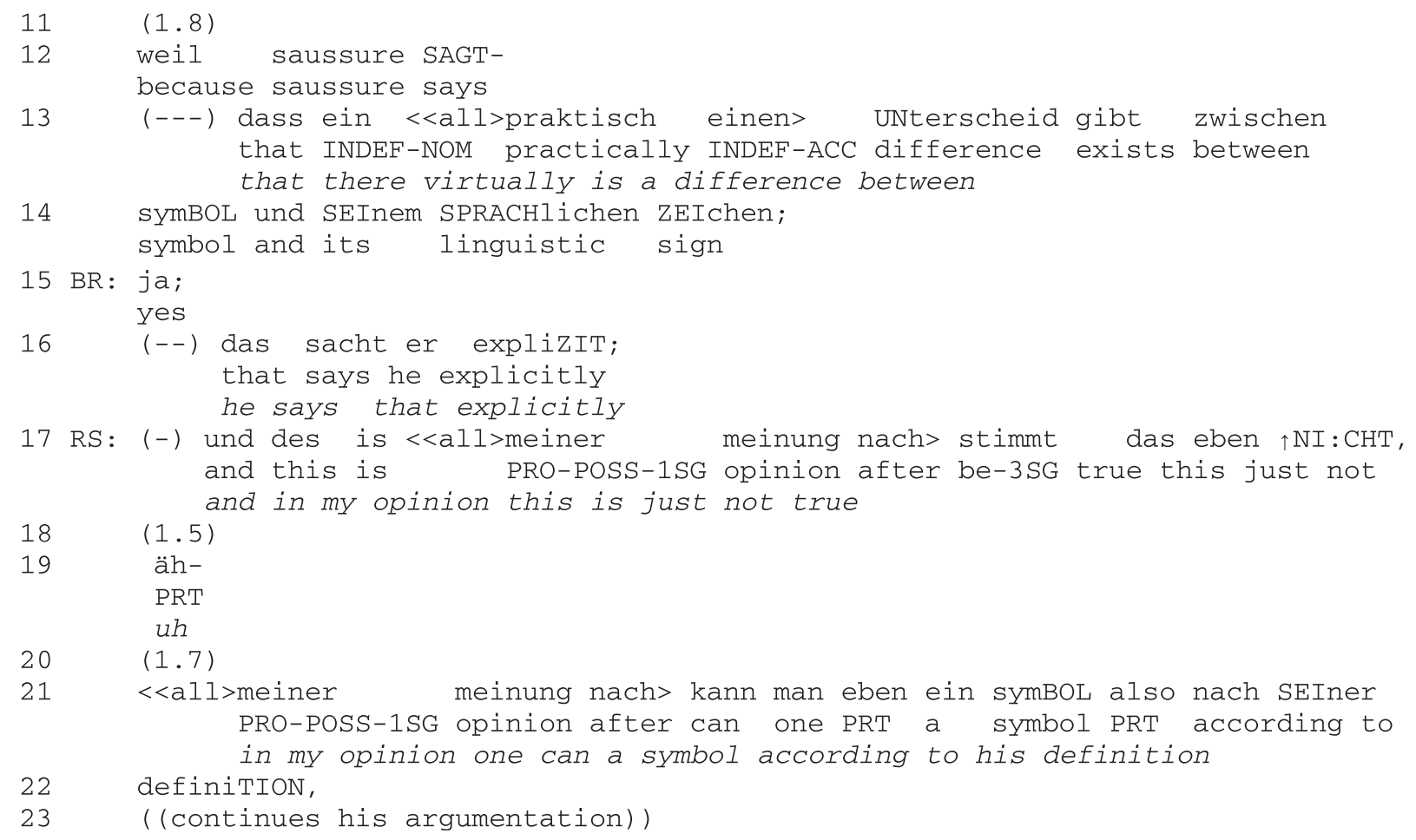

Extract \#1 shows an ambiguity between an epistemic and a normative meaning of verstehen which is systematically deployed over an extended argumentation. The meaning of da versteh ich nicht ('there I don't understand', line 07) at first seems to be epistemical in terms of "not to grasp the semantics", because the student prefaces his account with the announcement of a question (line 01-05). Then, however, he self-repairs da versteh ich nicht by halt ich des eben>- (- - -) äh in <<all>geWISser weis>für FA:LSCH, ('I just simply regard this to be wrong in a certain way'; lines 08-09). The self-repair points to a different, normative meaning of versteh ich nicht, namely, "not to accept a position". The student reformulates de Saussure's position and then gives an account of why he does not accept Saussure's notion of the "symbol" (lines 10-14). The student thus uses versteh ich nicht to refer to something which he grasps semantically, but which is argumentatively flawed from his point of view. In what follows, however, the student makes clear that his lengthy argument is designed to clarify with the professor's help whether there are reasons in favor of Saussure's position. The pragmatics of $d a$ versteh ich nich, thus, is not a plain rejection, but a conditional one, which is presented as being negotiable in the light of additional justification of the disputed view. Da versteh ich nicht projects the search for such a justification. Extract \#1 thus shows how semantic and normative meanings of nicht verstehen shade into one another, linked by an argumentative meaning "not to see/accept the reasons", which makes verstehen dependent on the availability of "good reasons" for some statement or action. Thus, the comprehensibility of actions and formulations is treated as being dependent on the intelligibility and acceptability of the reasons which can be recovered for them. Because of this inextricable link between semantic and argumentative connotations, the negative construction can be used to refer to both semantic and argumentative problems. $^{2}$

A specific argumentative environment for the negative construction is its use for framing a reproach or an objection which refers to a contradiction in the opponent's position which makes his/her argument look flawed. The contradiction is formulated in an adversative turn-format. A case in point is Extract \#2, which is from a mediation session. A1 protests against being fired because of absenteeism from work without a valid excuse. As evidence, her employer (B1) describes how she went to a coffee shop while A1 allegedly missed work for a doctor's visit.

\footnotetext{
2 See Deppermann (2005) on the reflexivity of semantics and argumentation in conversation.
} 
\#2 IDS-AGD Schlichtung 3003.119.3_00.12.46-00.13.2101 (kaffee)

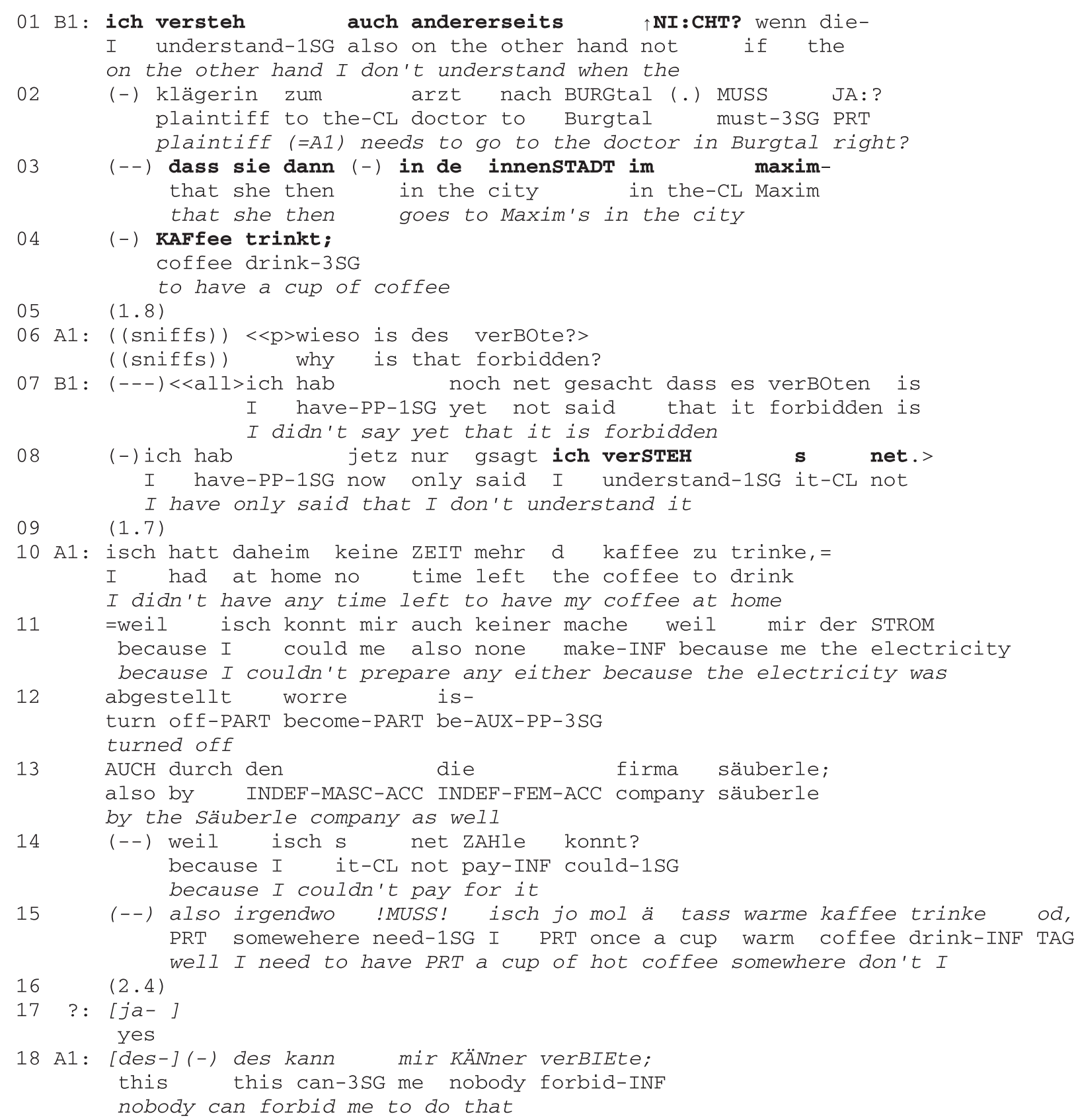

By contrasting the necessity of going to the doctor with going to a coffee shop (lines 01-04), B1 makes clear that ich verstehe (( ...)) NICHT (line 01) locally means "I cannot see/accept the reasons" for A1's action. A1 treats this as a reproach: wieso is das verBOte? ('why is that forbidden?', line 06). This response presupposes that B1 meant that going to a coffee shop is forbidden when one has to go to the doctor. B1, however, rejects this interpretation of his prior turn: ich hab jetz (-) nur gsagt ich verSTEH s net ('I now only said that I don't understand it', lines 07-08). B1 insists on a "literal" interpretation. He denies the categorization of his own prior turn as a reproach by (re)categorizing it as a repair-initiation, referring to a problem of understanding. The negative construction is thus framed as a request for justification. A1 delivers this justification in her next turn (lines 10-15), and when she does not receive an uptake (cf. the $2.4 \mathrm{~s}$ pause in line 16), she explicitly rejects the reproach (des kann mir KÄNner verBIEte; 'nobody can forbid me to do that', line 18). 
Extract \#2 again shows how the negative verstehen-construction can be systematically ambiguous regarding the action performed by it. It can be understood as a conventional way of producing a reproach, but this interpretation is always defeasible by reference to the lexical semantics of verstehen. Participants can operate either with an idiomatic, non-compositional meaning of the negative construction as such, amounting to a normative reproach, or with a compositional, lexically-based, epistemic meaning of verstehen in terms of 'not being able to see/accept the reasons'. As extract \#2 shows, participants can argue about which meaning was intended. Similar to warum ('why')-questions (see Günthner, 1996), the negative verstehen-construction is a rhetorical resource which can be used for conventionally conveying a reproach without needing to defend this interpretation, because the speaker can always (re)interpret his/her turn as a nextturn repair-initiator displaying a lack of understanding and calling for some justification. In the interactional sequence, turns with the negative verstehen-construction therefore often remain ambiguous. The more general rationale for the rhetorical potential of the negative verstehen-construction seems to lie in the culturally deeply entrenched rationalist ideology that the normative acceptability of some action or position needs to be based on its intelligibility. To be sure, this ideology does not explain how discursive acts come to be constituted in the first place. Still, it is a basic normative presumption which is virtually impossible to deny. Therefore, it provides powerful rhetorically discursive tools operating on the (non-)fulfilment of this intelligibility-condition for dealing with issues of (non-)acceptance of actions and positions in interaction.

\subsubsection{The discourse marker [verstehen sie/verstehst (du)/versteht ihr?] ('do you understand?')}

Neither the semantics nor the pragmatic functions and the rhetorical potentials of mental predicates like verstehen rely solely on the mental predicate itself. Rather, the grammatical construction in which the lexeme takes part can at least co-determine the locally relevant properties of the mental predicate. This becomes clear when comparing the negative verstehen-constructions with the use of verstehen in the context of the discourse marker construction [verstehen sie/ verstehst ( $\mathrm{du}$ )/versteht ihr?] ('do you understand?'). This construction is regularly used turn-initially in an insisting response following a partner's turn which the speaker regards as an insufficient uptake of his own prior turn. Extract \#3 from a seminar at a film school is an example. Two professors and four students discuss a script for a film. The professor had criticized the opinion of one student, who claimed that a pickpocket would not be prestigious enough as a good protagonist. The professor argues that a good plot does not depend on a glamorous hero, but rather that there is a lot at stake for the protagonist. When one of the students confirms this, the professor insistently repeats his objection.

\#3: Pitching: Taschendieb_00:28:01-00:29:09

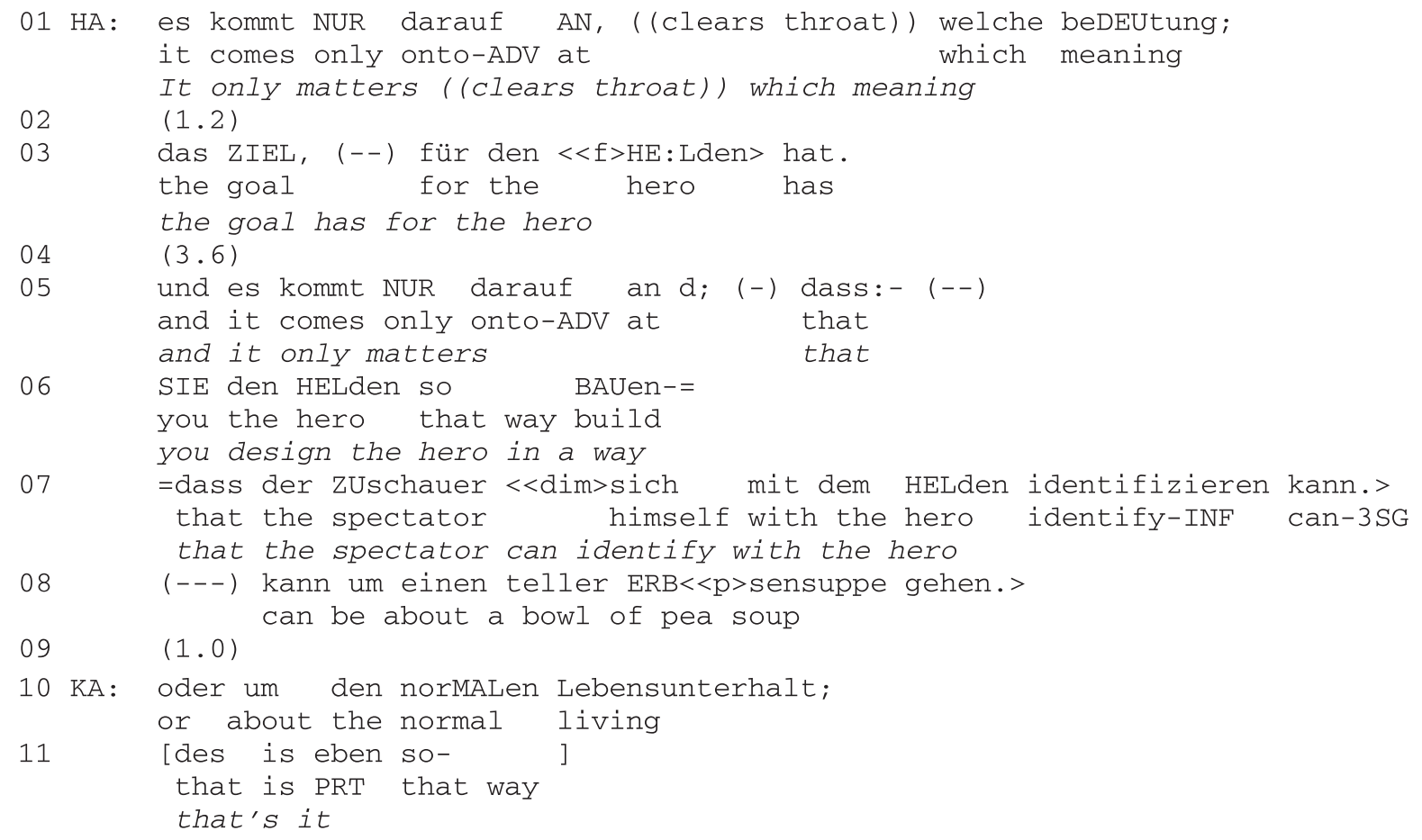




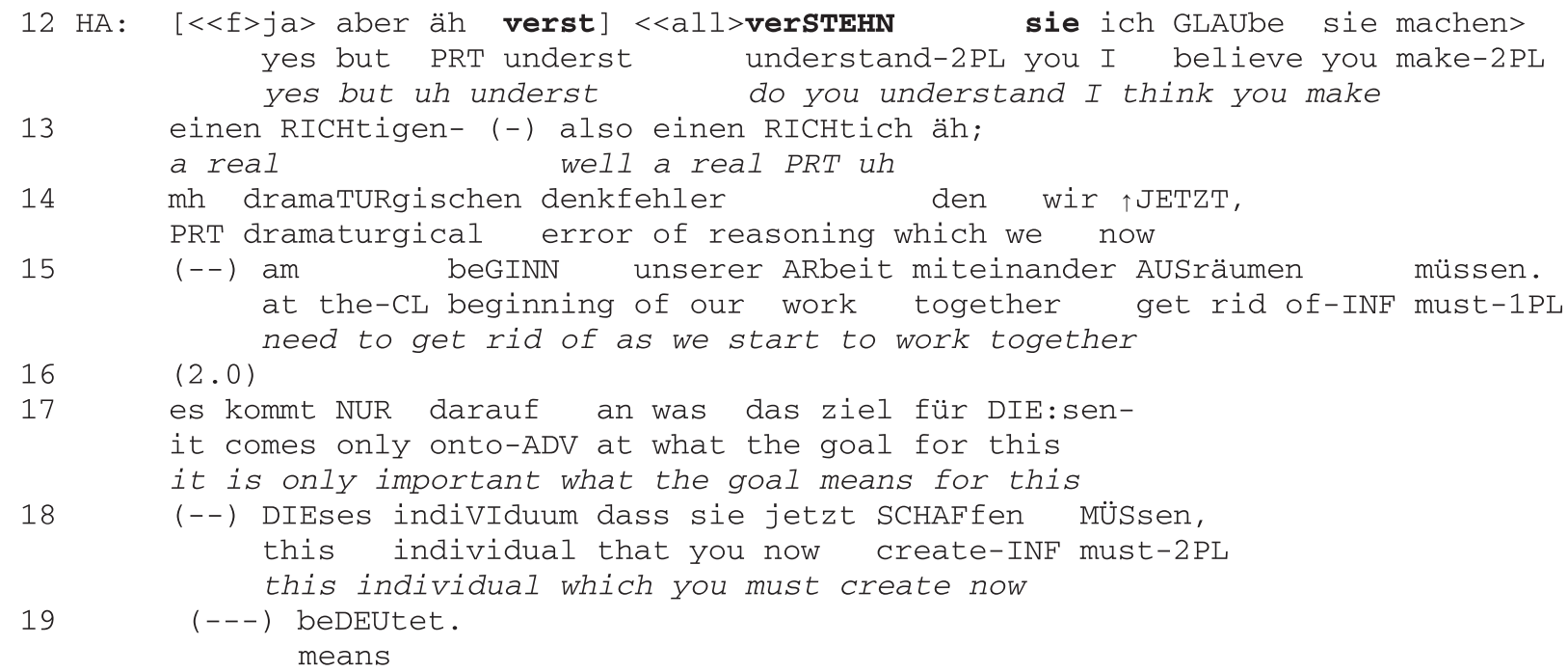

The extract starts with a professor's instruction (lines 01-08) on how to construct a protagonist. The student KA confirms this instruction by reformulating the upshot (lines 10-11). Obviously, the professor does not accept her turn as a sufficient display of understanding. In particular, the rather vague reference to normalen lebensunterhalt ('normal living', line 10) runs counter to a maxim which the professor advocates (not in this extract), namely, that a character needs to be created with reference to concrete actions. The professor responds to the student's reformulation with an adversative turn: ja aber verst verstehn sie (line 12). The turn-beginning is produced in overlap with the student's reaction; it displays the assumption that the student still has not understood the instruction well enough. The recycled turn-beginning and its prosodic integration with the upcoming turn shows that the professor is not using verstehen sie to elicit a response, but that he is projecting a reformulation. After criticizing the students' conception as a dramaturgical error of reasoning, (dramaturgischen denkfehler, line 14), the professor delivers the reformulation in lines 17-19. By repetition of the formula es kommt nur darauf an ('it only matters', line 17, cf. lines 01 and 05 ), the turn which is prefaced by verstehen sie? thus consists of an upgraded reformulation of the prior criticism.

Verstehst $d u$ ? is a discourse marker construction, which is used here in a canonical sequential pattern, which runs like this:

1. A: Main point.

2. B: Inadequate uptake (from A's point of view).

3. A: Verstehst du?

4. Reformulation of main point.

5. B: Repair of uptake.

Verstehst $d u$ ?-constructions are used when the achievement of intersubjectivity becomes problematic. They occur in the context of repeated initiatives and repeated accounts of positions which B reacts to only minimally or not in the way A expects. Such problems arise when

- B overtly rejects A's position.

- B produces reactions which make it obvious for A that B lacks relevant knowledge and misunderstands A's prior turns.

- B does not respond at several TRPs.

- B departs in his behavior from essential normative expectations, so that A starts to doubt whether B can be regarded as a competent member.

In the discourse marker construction, the lexical semantics of the verb verstehen is still present, albeit in the negative: Adequate understanding on the part of the listener has not yet been reached from the speaker's point of view. The professor allocates the students a task of understanding, which is cognitive (denkfehler, 'error of reasoning', line 14), but also practical, because it calls for a practical accomplishment (schaffen müssen, 'must create', line 18). So, not only the meaning of "grasping intellectually" is at issue, but also the meaning of "acceptance" and "confirmation of knowledge". 
However, there are also uses of verstehst du?, in which the semantics of the verb verstehen is "bleached", i.e., the discourse marker construction only has a discourse organizational function, but no more semantic content. When a speaker produces a thematic digression, verstehst $d u$ ? can be used to reorient the listener to the main line of talk and to project its continuation. It thus turns the comment into a parenthesis which deserves no further attention. An example is Extract \#4 from a talk show. The entertainer Karl Moik (KM) tells how he became an anchorman for folk music shows on TV.

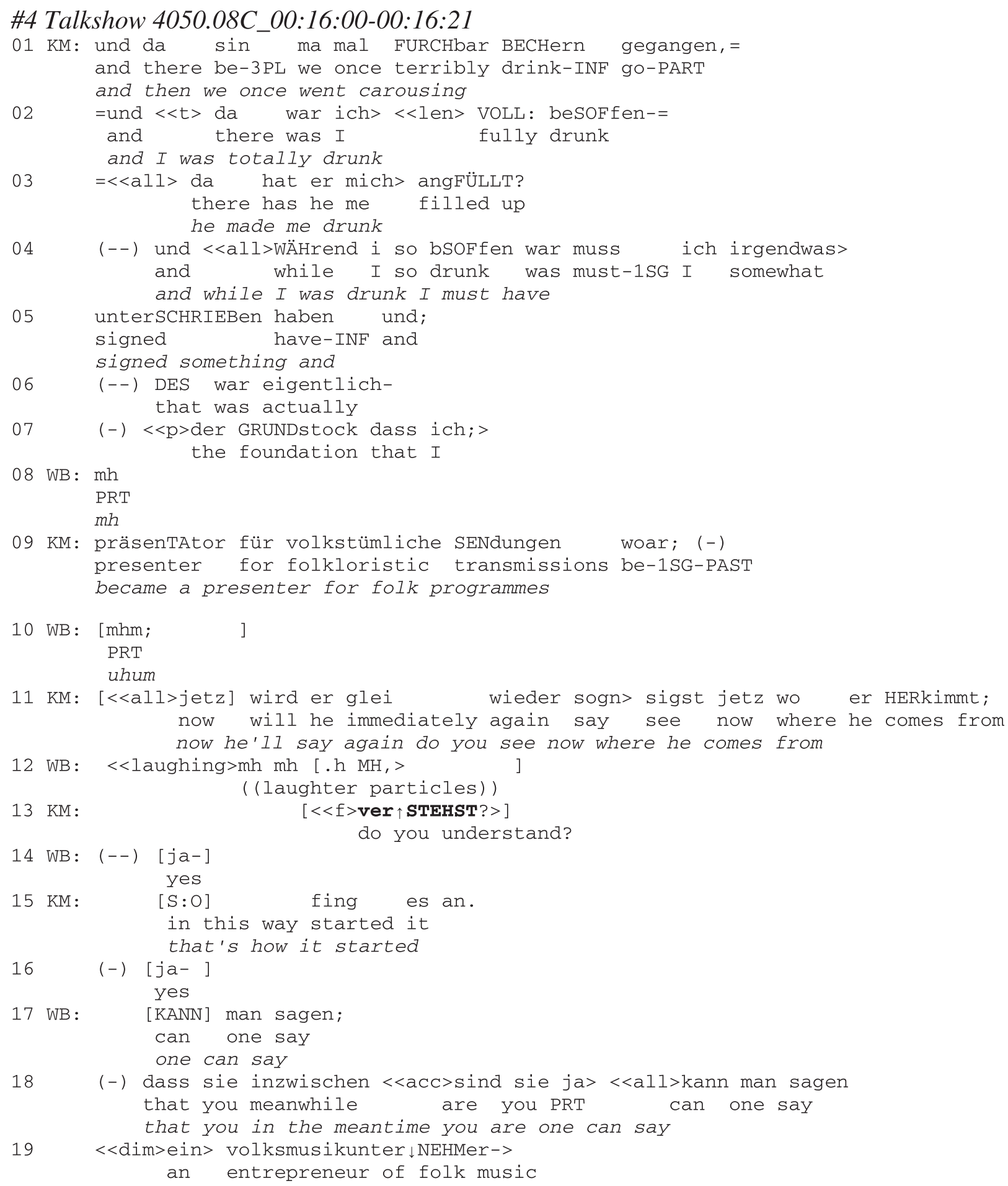


Having concluded his story (lines 06-07), Moik adds a derogatory comment which he attributes to his interlocutor, the interviewer Wilfried Backes (WB), adumbrating that Backes will interpret Moik's account of being drunk as typical of his personality. Backes' laughter (line 12) indicates that he recognizes and shares the jocular key. Moik, however, does not laugh. With a loud verstehst? (line 13), which is produced in overlap with Backes' laughter, he reorients to his story und with the coda-formula so fing es an ('that's how it started', line 15), and underlines once again the point of his story. Like in Extract \#3, verstehst? is used to advert the recipient to the main point of an account, which is referred to anaphorically: SO: fing es an ('that's how it started', line 15). Verstehst? indexes that the jocular comment and the recipient's response are to be treated as an insertion, and the recipient is reoriented to the fact that it is the story, and not the comment, which the recipient should respond to and which will be the subject of the speaker's next action.

In such cases, verstehst du? is used as a resumption marker (cf. Mazeland and Huiskes, 2001). It is used as a means to segment the speaker's own talk and to signal turn-internal coherence relations, i.e. a shift back to a prior focus or topic. The sequential pattern for the use of verstehst $d u$ ? as a resumption marker is:

1. A: Focus 1 (main point).

2. A: Focus 2 (digression).

(2a. B: Uptake of focus 2).

3. A: Verstehst du?

4. A: Focus 1 (reformulation of main point).

5. B: Uptake of focus 1.

The function of verstehst $d u$ ? as a resumption marker is remote from the lexico-semantic origin of the lemma verstehen. The formula here is not used for achieving intersubjectivity, but it indexes what the addressee should treat as the main point of a turn. In this sense, s/he should understand (verstehen) what matters most concerning the speaker's turn.

\subsection{Doing drawing inferences from the partner's prior turn}

Participants in an interaction have various resources for displaying that they understand the partner's prior turn. These include acknowledgement tokens (such as $\mathrm{mhm}$ and yes), change-of-state tokens (oh, German achso), repetitions, displays of emotional empathy and affiliation, collaborative turn-completions, and performing a projected next action, which presupposes a proper understanding of the partner's prior turn (Deppermann, 2008). While some of these displays amount to a mere claim to understanding without proving it to be the case, the formulation of an inference drawn from the partner's turn gives him/her the opportunity to check and confirm whether s/he goes along with the interpretation conferred. In terms of sequential organization of the interaction, the formulation of an inference does not simply give one possibly correct interpretation, it is produced as a reformulation expressing the most important gist, upshot, or otherwise relevant aspect of the turn, upon which further talk is to be based (Heritage and Watson, 1979). So, making an inference explicit is more than an overt display of understanding as a cognitive activity. It is a practically designed action, which refashions the prior turn according to the practical purposes of the second speaker (see Drew, 2003), and it is a powerful tool for manoeuvring interactional trajectories. In what follows, two different practices of doing drawing an inference are contrasted: the first is explicating inferences, the second is delivering a subjective interpretation.

\subsubsection{Explicating inferences with also-reformulations}

With this practice, speaker B formulates an inference from the immediately prior (or more) turn(s) of his/her partner A. This inferred meaning is presented as representing what A meant, i.e., (a part of) the communicative meaning in a reflexive Gricean sense (Grice, 1975). The explicating turn is linked to the prior turn by the connective and discourse marker also. ${ }^{3}$

Extract \#5 is from a behavior therapy. An HIV-patient talks about the situation of his partner, who is also HIV-positive.

\footnotetext{
${ }^{3}$ An in-depth analysis of this practice can be found in Deppermann (2011b).
} 


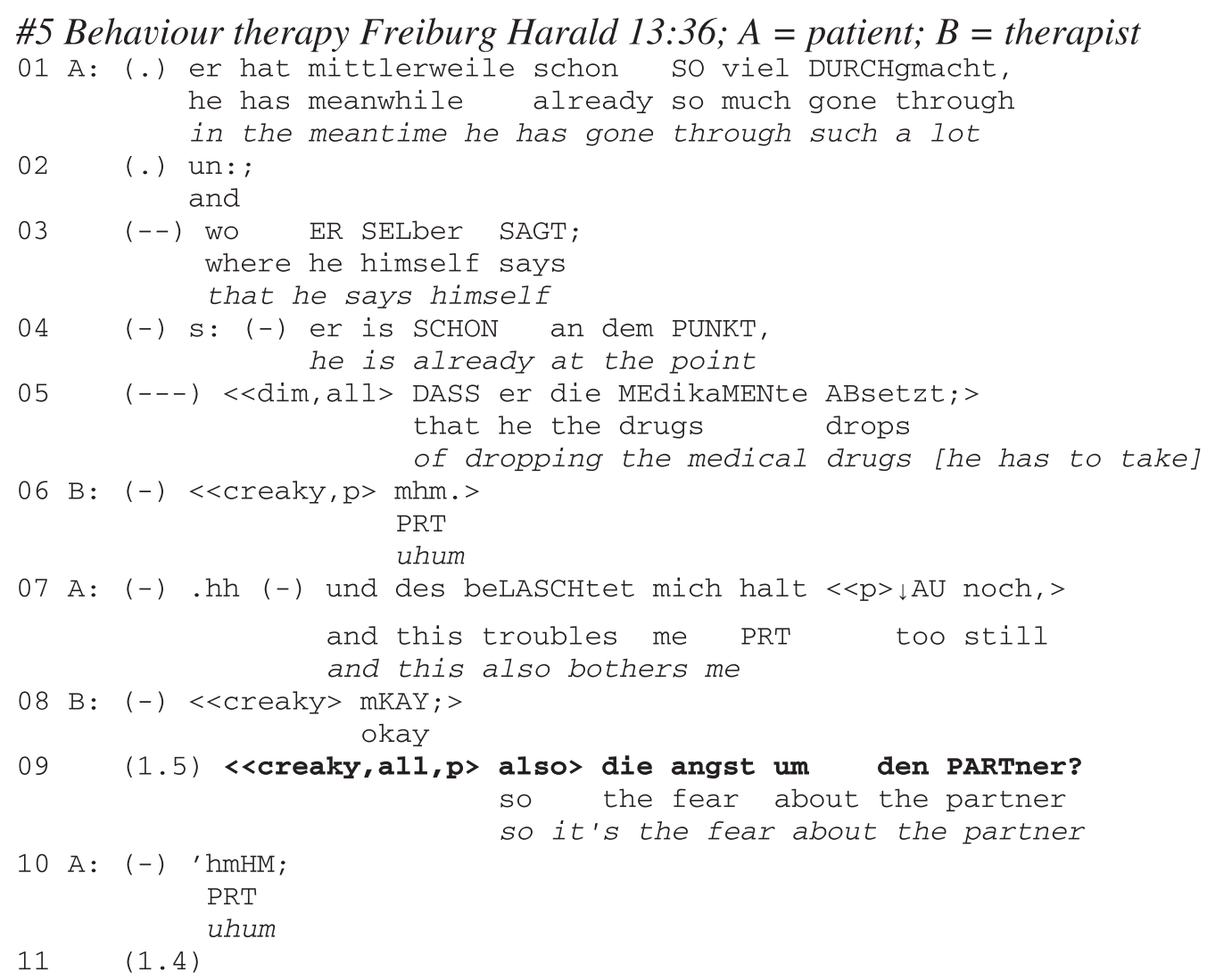

The second example is also from a psychotherapy session. The patient talks about her relationship to her mother.

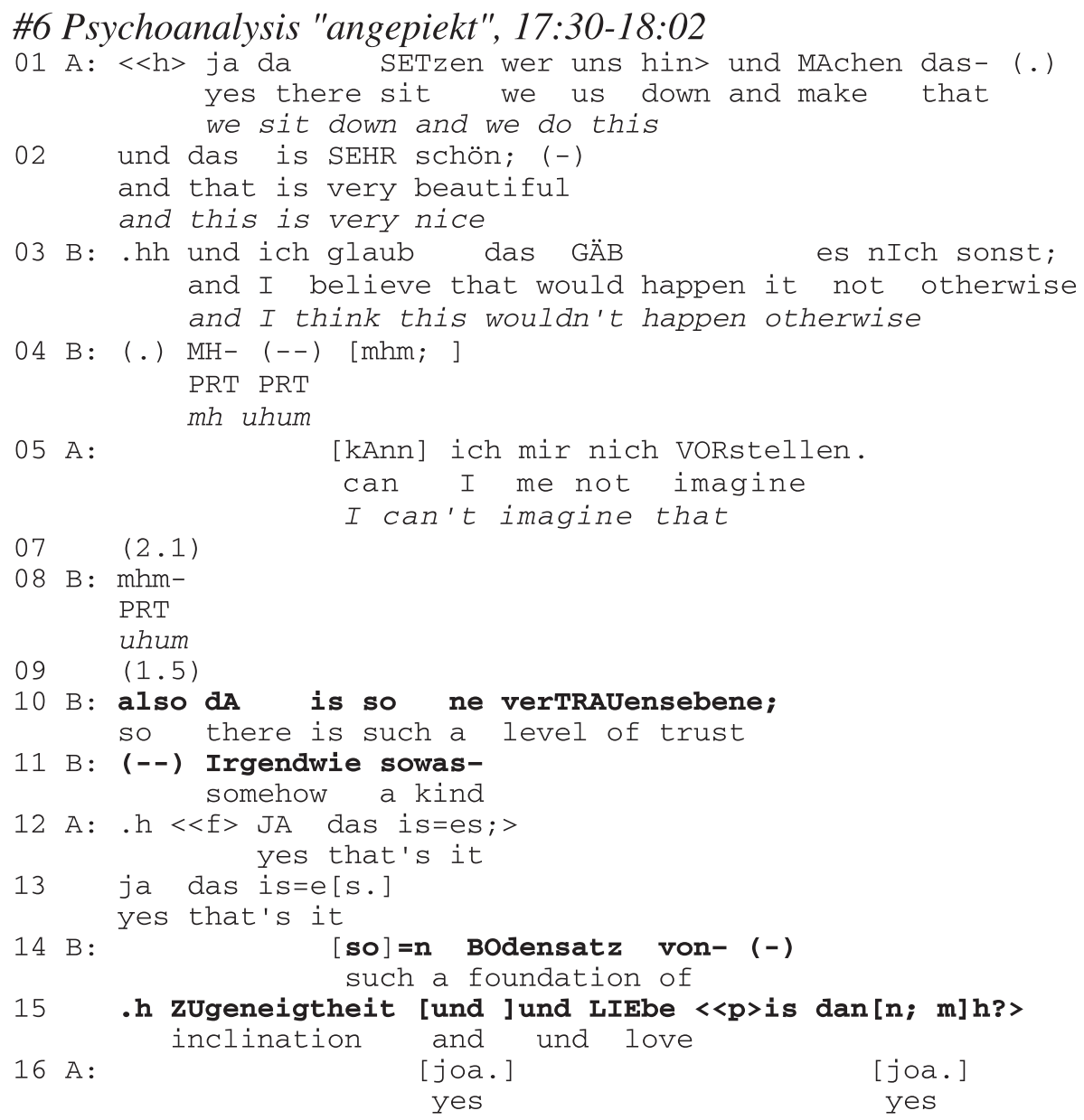


In both examples speaker A produces a first version of some state of affairs. Speaker B then reformulates this, linking his/ her turn back to the partner's prior turn by turn-initial also. ${ }^{4}$ The formulation is produced as the explication of an inference from the first version; there is neither hedging nor is the reformulation specifically marked as displaying a subjective perspective of B. The formulation is presented as an understanding-check which projects confirmation from the producer of the first version. The formulation transforms a somewhat more detailed and often vague description or a narrative into a condensed, clear-cut categorization in psychological terms. This last feature shows how the specific way in which explicating inferences is done is neatly tailored to the practical business of the talk, in this case of psychotherapy. It extracts the therapy-relevant aspects from the patient's account, focusing on them as its relevant meaning, which has to be retained.

\subsubsection{Delivering a subjective interpretation}

Explicating inferences is in clear contrast to another practice of displaying understanding by expressing an inference from the partner's talk, namely, delivering a markedly subjective interpretation from B's point of view. Although it is also produced as an inference from A's prior talk, it neither purports to represent A's intended meaning nor does it establish a strong preference for confirmation as A's next turn. Here is an example:

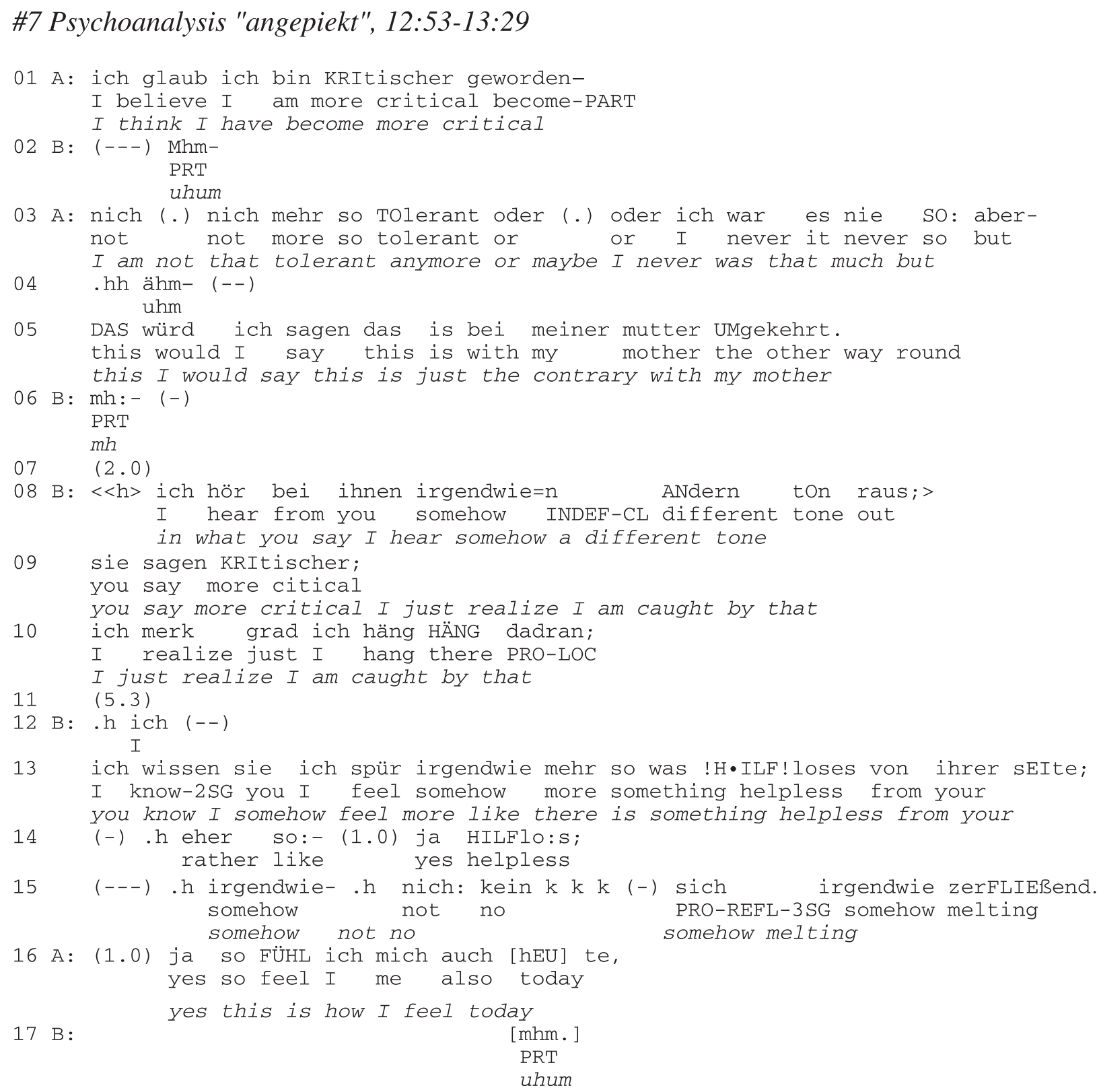

\footnotetext{
${ }^{4}$ As can be seen in the data, also is often preceded by a pre-turn acknowledgement token like okay, mhm, and gut.
} 
This practice of delivering a subjective interpretation of A's turn(s) from B's point of view contrasts clearly with the practice of explicating inferences discussed in Section 5.2.1:

- B's particular subjective epistemic perspective is explicitly marked by the use of verbs of perception and cognition (ich hör bei ihnen irgendwie $=n$ andern ton raus, line 08; ich merk, line 10; ich spür, line 13).

- Numerous mitigators (irgendwie, lines 08, 10,13,15), cut-off (line 12), self-repair (line 14), and gradual terms (mehr so, line 13; eher so, line 14) indicate vagueness, uncertainty, and negotiability of the adequacy of lexical choice and of the validity of assertions.

- B quotes a part of A's prior turns (sie sagen kritischer, line 09), indicating where and how her own interpretation departs from and contrasts with quoted items. These quotes isolate and re-contextualize specific parts of A's prior turns, relating them to parts of A's talk different from A herself, as in the extract, to B's subjective perceptions of A, which are not treated as being part of what $A$ intends to communicate (lines 09-15).

- B produces a lengthy multi-unit turn, deliberating on different facets of interpretation which can be seen to elaborate and account for each other mutually.

While in the case of explicating inferences, B purports to explicate some intended, intersubjectively implied meaning which A has communicated with her/his first version, in the case of formulating a subjective, external interpretation, B draws an inference which is displayed to be motivated from A's first version and B's independent frame of reference and which is not presented as an evident and already intersubjectively valid version. Explicating inferences derives its rhetorical potential precisely from the fact that it purports to do nothing more than to bring out in the clear what is already implicitly there in the prior turn. The formulation of a subjective interpretation, however, requires a lot more caution and accounting work in order to be framed as being acceptable to the patient, because it is not (and reasonably cannot be) framed as an upshot which has been meant and is already known to the patient.

\section{The inevitability of cognitive assumptions and their limitations in CA and DP}

The growing body of studies from the constructivist, anti-essentialist point of view which CA and DP take with regard to cognition testifies a prosperous line of research. It shows how 'cognition' figures in language and interaction, and by this, elucidates its role in different fields of everyday social practice. Being agnostic about the reality and nature of cognitive processes which might inform interaction and thus refusing any mental speculation as part of the analysis seems to be a methodologically warranted position, because it avoids introducing concepts into the analysis which cannot be grounded in the details of the talk. In this way, CA and DP do not rely on theoretically derived models, which presuppose assumptions and a descriptive apparatus which exceeds by far what can be shown to be the case in the data.

However, I would like to argue that tacit assumptions about cognitive processes are nevertheless present in the analyses in both CA and DP, and I will try to show that this is inevitably so. But whether cognitive assumptions need to be part of the analysis, then we should try to reach a better understanding of how and why they figure in the analysis, and we need to find ways to be explicit about them and to put them to the test. Moreover, I will take the position that making cognitive assumptions explicit does not only enhance the explicitness and the descriptive adequacy of CA and DP analysis. It also opens up new directions of research and findings, which relate action in interaction to cognitive processes. In this way, they might enhance both our understanding of cognitive functioning and of talk-in-interaction.

The conversational "machinery" (Sacks, 1984) does not work by itself, but only with participants who dispose of necessary perceptions, knowledge, and motivation. For every analysis of talk-in-interaction, a whole range of specific, situated assumptions about the participants' cognitive states and processes are necessary in order to describe their actions (cf. Levinson, 1995, 2006). The analyst cannot do otherwise but make assumptions about participants' attention, visual and auditory perception, semantic interpretation, inferences, pragmatic expectations, and memory - to name only the most basic domains of cognition, which come into play in virtually every analysis. It is not the case that these are just general prerequisites of cognitive functioning which can be taken for granted in the analysis, because they would belong to some "normal input and output conditions" (Searle, 1969, p. 57), which had to be presupposed for every working of the conversational machinery in the same way. I will return to a closer analysis of one of the cases already examined in order to show that cognitive assumptions, in particular regarding inferences to participants' understandings, are inevitably built into the analysis of action (Section 6.1). However, some cognitive ascriptions which might be interesting to make cannot be accounted for by dataanalysis (Section 6.2). Cognitive ascriptions can be shown to be necessary both for conceptual reasons and with references to specific instances of situated interaction (Section 6.3). The article closes with some summarizing remarks about when cognitive ascription is necessary for interaction analysis (Section 6.4).

\subsection{The ascription of inferences to the participants in the analysis of an interactional sequence}

The inevitability of cognitive assumptions will be shown by revisiting the analysis of the negative verstehen-construction. In order to see how cognitive assumptions necessarily come into play in sequential analysis, I will return to \#2 as an example. 


\section{\#2 IDS-AGD Schlichtung 3003.119.3_00.12.46-00.13.2101 (kaffee)}

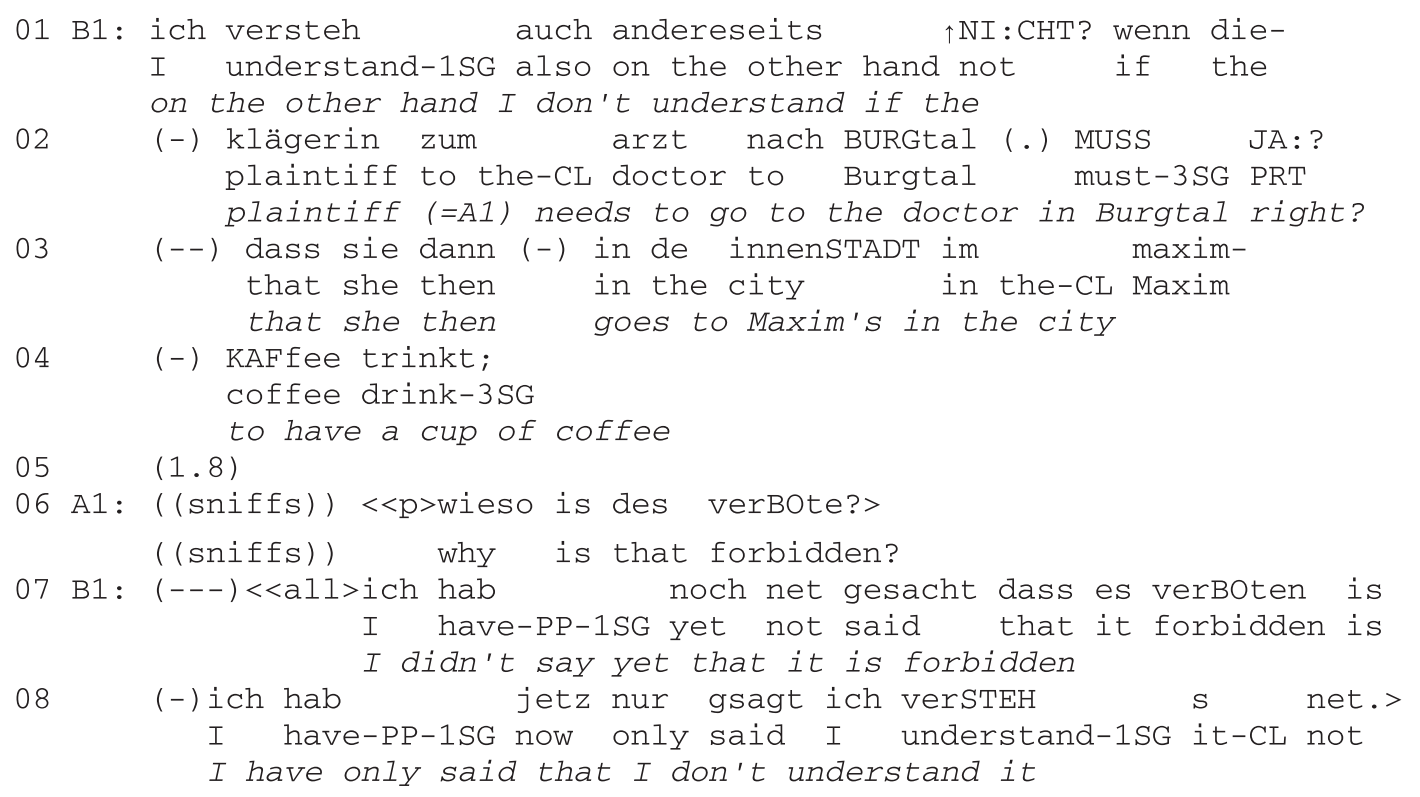

To understand A1's response in line 06 as a 'challenge' implies that she has listened to B1 (attention), heard him unimpededly (perception), and interpreted his reference to herself (die antragstellerin, 'the plaintiff') correctly (encyclopaedic knowledge). While these cognitive prerequisites sound utterly trivial and unspecific for the 'challenge', there are some further cognitive achievements, which are indeed vital and specific for providing grounds for a challenge as a next action. A1 must understand

(1) that B1's turn imputes a contradiction (although he does not use an overt marker),

(2) that this contradiction is evaluated negatively by ich versteh nicht (and not (only) as a cognitive problem of understanding),

(3) that the problem causing the contradiction is located in a normatively inadequate behavior on her part, which she would have had to avoid (=to go to a coffee bar in the city when she should take the direct way to the doctor's),

(4) that this amounts to a reproach of B1's action,

(5) (that this is part of B1's justification for firing her, thus attributing the blame for this result to herself).

The relevance of the ascription of these inferences becomes more evident when we dive deeper into potential ambiguities of the interactional sequence. A1 uses a next-turn repair initiator (NTRI), asking for a justification of something which B1 actually did not say (wieso is des verbote, "why is that forbidden?"). In this sequential position, the turn is ambiguous whether it is actually used as a challenge, projecting a back-down by B1, or as a request for justification. Both possible actions presuppose the kind of inferential reasoning outlined in points (1)-(4) above, and they both imply that A1 takes B1 to mean that it was forbidden to go to a coffee bar when she was ill. However, it is still possible that A1 assumes that B1 did not intend to mean this, but that A1 strategically ascribes an exaggerated position to B1 (very much like constructing a "straw man"), which might be easier to rebut. While this cannot be decided from the sequence, it is clear that there is another alternative: A1 might not have inferred an unstated intention from B1's turn, but there might simply have been a mishearing when she asks wieso is des verbote.

This is precisely how B1 treats it: He refuses the presupposition that he had said that it was forbidden for A1 to go to the coffee shop (ich hab jetzt noch net gesagt dass es verbote is, "I didn't say yet that it is forbidden"). However, B1's correction simultaneously shows that A1's understanding of B1's moral position (verbote) is not simply a mishearing, but that it might indeed become factual in the future (maybe depending on how A1 accounts for the morally implicative contradiction B1 has constructed in his prior turn, lines 01-05). A1 goes onto provide an account, which is to justify her going to the coffee bar. Giving this normalizing reason gives evidence that she had understood that B1 accused her of behaving inconsistently, because she provides an argument which can resolve the contradiction which she obviously understands B1 to have sketched. A1 formulates the moral upshot of her counter-argument by closing it with the conclusion des kann mir käner verbiete ("nobody can forbid me to do that", line 18). She now makes her own normative stance explicit, using the same category verbiete as before. The stance-displaying conclusion makes clear that her earlier NTRI was not used to elicit a clarification and maybe not even a justification from B1's part, but as a pre-disagreement with B1's reproach, pointing to an implicated objection very much in the way of a rhetorical question, which defeats B1's construction of a morally inadequate behavior. 
A1's inferential work is not just something we can reconstruct as an addendum to the analysis of what is being done in the interaction. Just the contrary: This analysis of A1's inferences is an integral part of the analysis of her action. We must already implicitly have carried it out when arriving at the interpretation that A1 produces a 'challenge' and that she produces a 'counter-argument', because it is part of the situated meaning of these actions in terms of Sacks' question "why that now?" (see Bilmes, 1985). In general, assumptions about 'inferences' are basic ingredients of understandings displayed by subsequent turns, and these understandings themselves are crucial for the categorization of what the subsequent turn does in terms of action(s).

\subsection{Uncertainties and limitations regarding cognitive ascriptions}

The first four of the five possible inferences which A1 may have drawn from B's turn listed in Section 6.1 are pragmatic inferences, which B1 must be taken to make in order to hear her reply as a 'challenge'. I bracketed the fifth possibility in order to indicate that this inference could have been made, but that there is no way to judge from her turns that A1 does so. With the same degree of plausibility and yet uncertainty, we can add that she interprets the contrast which B1 constructs as a violation of moral norms for the behavior of ill people, because the predication zum arzt muss ("has to got to the doctor") invokes the duties of the patient's role (very much in the sense of Parsons (1951, Chapter 10)). So, here social knowledge of the logics of (a potential version of) category-bound actions of the category 'patient' and its liabilities (to go directly to the doctor without detour) might be in play. But again, there is no sufficient evidence that A1 infers this category-bound normative expectation from B1's turn. We can see here that it is hard to pin down exactly which inferences A1 has made, i.e., their precise content, how far reaching they were (e.g., whether she understands B1's argumentation as a local move or as a strategic one which is instrumental to his general position in the conflict) and at which precise point in time before her challenge they were made. The interactional surface is far from being wholly transparent with regard to underlying cognitive processes. It is always indexical, i.e., underspecified, partial, and vague with regard to the precise set of indexed assumptions (cf. Garfinkel, 1967). However, we can distinguish a core of inferential work which is an indispensable prerequisite for producing the reaction and for its interpretation as a challenge.

Let us now deal with another cognitive assumption which might be relevant for \#2, namely, the attribution of 'strategy'. The rhetorical potential of the negative verstehen-construction makes it amenable to strategic uses, i.e., to calculate on its ambiguity as a resource for producing defeasable reproaches, which can be re-interpreted as displays of problems of understanding. At first sight, we may be inclined to think that B1's use in line 01 is a case in point. It seems that he consciously exploits the ambiguity of the negative construction as the 'reproach'-meaning gets challenged by claiming the "literal meaning" of an understanding problem (line 06-07). That there may be a strategy in play is further corroborated by the fact that his other actions related to the issue (in particular: B1 fired A because of her absenteeism) all express a negative moral assessment of A1's action and thus strongly support the 'reproach'-meaning as his "real stance" towards the issue. Thus the speaker's denial of this meaning (line 08) might seem a shallow exploitation of a constructional ambiguity, which is not credible. However, we cannot know if things are like this. First, if we ascribe a strategy which implies the calculation of rhetorical options and effects, we presuppose that this is done consciously. Methodologically, however, it is impossible to verify in most cases that and when conscious reasoning takes place in bringing about discursive actions (cf. Heritage, 1990/91; Drew, 1995), and it might be doubtful whether it can be verified at all (Hopper, 2006). In the corpus investigated, the negative verstehen-construction is used as a routine practice in the context of arguments which are framed as rational disputes, e.g., in TV-discussions, legal interactions, and mediation sessions like \#2. It thus seems to have become routine just because of its rhetorical merits and its in-built caution regarding moral stance-taking. Speakers may have learnt to use it this way, perhaps also because it is a stylistically marked practice, which is preferential over overt reproaches in settings like in \#2. Hence, there is no need to assume any conscious strategy on the speaker's part, when s/he only exploits the potentials of a practice which has become routine because of these potentials. Secondly, we cannot be sure either, whether B1's denial of the 'reproach'-interpretation is strategic. It may well be the case that he uses the negative verstehen-construction to point to a lack of good reasons for A1's action of going to a coffee bar, giving her the opportunity to provide a justification in order to see whether she is able to refute his negative evaluation of her action.

\subsection{Phenomenological ascription and conceptual implication of cognitive processes}

The re-analysis of \#2 in terms of necessary inferences regarding how the participants understood each other has shown how cognitive assumptions are inevitable for the analysis of interactional episodes in terms of participants actions and their local understandings. Data need to be inspected concerning the cognitive ascriptions participants must be taken to be making regarding a conversational phenomenon at hand. This becomes most striking when dealing with video-data from multiparty interactions. Such data cannot be analyzed without continuously keeping track of who is attending to whom (and to what) and who perceives which event in a given moment and thus may use it as a basis for future action (cf., e.g., Schmitt and Deppermann, 2007; Norris, 2004). ${ }^{5}$ Another cognitive activity which is needed in almost every episode of talk-in-interaction is

\footnotetext{
5 This experience from work with video-data, which make participant's processes of attention and their perceptions available to the analyst to a much higher degree (although still not without a considerable range of indetermination, e.g., regarding gaze and eye-contact), lets us suspect that attention and perception might often be taken for granted too easily when working only with audio-data.
} 
anaphora resolution. As an example, in \#6, the analyst as well as the patient (A) must assume that the therapist (B) uses $d a$ in $d a$ is so ne vertrauensebene (line 05 ) anaphorically to co-refer to the relationship between the patient and her mother. Da is a complex anaphor (Consten et al., 2009) with no individual lexical antecedent. To use this form, we must take the therapist to have sorted out the agents of the story the patient told in her prior turn.

While the analysis of instances of interaction requires cognitive attributions to the participants, they are also implicitly built into the vocabulary of CA and DP in general. This is because nearly all action predicates imply ascriptions of intentionality (see Anscombe, 1957; Geertz, 1973). To be sure, the predicates themselves designate social concepts relating behavior to cognitive assumptions and social facts. As such, they do not refer to any individual person's mental state, but to cognitive states as generalized conceptual components of action predicates. Thus, if an action is predicated, ascriptions of intention (and still other cognitive states, such as epistemic stances) are implied as part of its (social) semantics. This, however, makes it necessary to attend in interaction analysis to all interactional details which allow for decisions which assumptions might apply to the participants in the case under study and, consequently, which actions can be said to be performed in an interactional episode. This requirement is not (basically?) changed by the CA-requirement that the researcher must not interpret from his/her own frame of reference, but that s/he has to discover how the participants interpret each other. To do this, we have to resort to action interpretations, which, although being subject to different proof criteria than overhearers' interpretations, still follow the same semantic logic of the ascription of intentions. How important the situated ascription of intentions, knowledge, etc. to participants is, is particularly evident by the fact that in particular CA, unlike speech act theory, does not rely on the notion of 'conventionality' for interpreting actions. Instead, they require the analyst to show how actions and their meanings are constructed as a contextual achievement, taking sequential, situational, recipient properties, etc. into account. This, however, forces the analyst to take the various kinds of participants' putative cognitive processes into account, because assumptions about coherence, projections, expectations, allusions, interactional concerns, what may be at stake for participants, etc. tacitly presuppose that these are realities which are cognitively grasped by the participants. So, even if conversation analysts and discursive psychologists are neither interested in cognitive processes as an object of study nor in modeling cognitive states of the participants, cognitive ascriptions inevitably come into play when analyzing data in order to reach an interpretation of what people are doing in an interactional sequence. Accordingly, the description of a practice necessarily implies cognitive assumptions about knowledge, goals, perceptions, etc. of the participants performing the practice.

\subsection{Some suggestions for how to deal with cognitive assumptions in CA and DP}

As DP argues, cognition cannot be simply read off from interactional conduct. Nevertheless, it necessarily figures in the analysis of interaction, especially with regard to the analysis of actions and displays of understanding, which both presuppose inferences in order to be possible and as part of their situated meaning in terms of their accountability. The reconstruction of inferences concerning possible understandings and intentions requires abductive inferential reasoning, which looks for sequentially (and otherwise) reasonable understandings and intentions as premises for behaviors and their interpretation as actions (cf. Levinson, 1995). Cognition has an indirect status with regard to interaction: Cognitive ascriptions are implicitly built into analytic ascriptions as their necessary prerequisites, both conceptually regarding the semantics of analytic terms and with reference to the behavior of participants in interactional episodes.

Although cognitive ascriptions cannot be derived directly from observable behavior, they can be shown to be procedural and interpretative prerequisites and implications of the actions and practices. So, an agnostic stance towards cognition and even more so a straightforward anti-mentalistic stance seem to be conceptually flawed and phenomenologically inexplicit, because they both inevitably presuppose cognitive processes of various kinds to be the case for being able to use their own (pragmatic) predicates of analysis. ${ }^{6}$ Being more explicit about cognitive ascriptions would lead to a more comprehensive analysis and description of practices. Instead of seemingly banning cognitive speculation from the outset (while still relying on it), attending more systematically to when, how, in which way, by which observable warrants and by which conceptual necessities cognition comes into play in interaction and its analysis can make hidden presuppositions disputable and refinable, and can give access to additional orders of meaning and motivation, which might allow for discovering hidden and otherwise incomprehensible features of the talk.

Still, it is evident that cognitive assumptions need to be made with caution. We must be aware that the relationship between discourse and cognition is at best oblique, relying on inferential procedures, which are mediated by many sources and which often cannot be verified. Often, it is hard to say whether the analyst's explication, even if it is perfectly consistent with the course of interaction, is an adequate expression of the participants' orientation. In particular, the search for conscious reasoning, planning, and strategy in interaction seems to be futile, because conscious processes which are not expressed as such seem to be impossible to prove by interactional data. We should neither ask the wrong questions about cognition, which cannot be answered with the help of interactional data, nor should we exclude all kinds of cognitive ascription, because we erroneously equate cognition with conscious reasoning. This line of defence, which proponents of a "pure" discursive approach like Coulter (2006) and Hopper (2006) seem to construct, suggests a wrong alternative. It rests on a notion of

\footnotetext{
${ }^{6}$ Moreover, overt cognitive ascriptions like $X$ understands, knows and seems to feel. figure regularly in analyses of CA and also DP, albeit evidently not as their conversational objects under study.
} 
cognition which no adherent of cognitive science would subscribe to and thus cannot be counted on in order to prove the inadequacy of a cognitive approach.

So, what may be criteria for when and how cognitive assumptions become relevant for CA or DP? To be sure, this is a question which would require much more detailed research, methodological argumentation, and data-driven, phenomenon-centred discussion than can be done here. I must restrict myself to outlining some basic principles which have proven to be relevant in prior studies:

(1) Since the ascription of inferences and intentions to participants rests on abductive, practical reasoning, which tries to recover rational grounds for observable actions, the analysis needs to rest on presupposable, commonsensical, social rationalities and encyclopaedic knowledge, which defines reality for "everyone". Such rationalities include understandings, motives, and goals which just anyone could have in the sequential context (Levinson, 2006; Sanders, 2006).

(2) Cognitive assumptions are necessary, if they contribute to maximizing the coherence between actions of one (or more) participants in a sequence and if they render details hearable/visible, intelligible and coherent which could not be accounted for otherwise (Deppermann, 2000).

(3) Just as cognitive assumptions might be necessary to create coherence among actions, the reverse relationship also holds: To assume coherence in participants' motives and definitions of reality (=cognition) might in some cases be indispensable to settle interpretations of talk-in-interaction (Sanders, 2006), which may remain elusive or indeterminate otherwise. Indeed, this assumption is virtually no different from the well-known "principle of charity" (e.g., Davidson, 1973), which has been advocated at least since Schleiermacher (1838 [1977]) in Hermeneutics and which lies also at the core of the Gricean concept of implicature (Grice, 1975; see Scholz, 2001 for a history of related concepts dating back to Antiquity). ${ }^{7}$

(4) In addition, and sometimes in contrast to (1), analyses of practices have to take into account for - and sometimes crucially rest on - what is the case for the specific participants in just this interaction. It may require ethnographic work (Deppermann, 2000) to recover participants' background assumptions and definitions of reality in order to analyze, e.g., epistemic practices (Heritage and Raymond, 2005) and fictional practices, like irony, and mock-stories, which rely on participants' definitions of reality.

(5) Claims about practices and actions must be compatible with what is possible in terms of cognitive processing and capacities (Sanders, 2006). This requirement implies to take into account research which studies cognitive processes that may be pertinent to producing some discursive action in question.

\section{Transcription conventions GAT (Selting et al., 2011)}

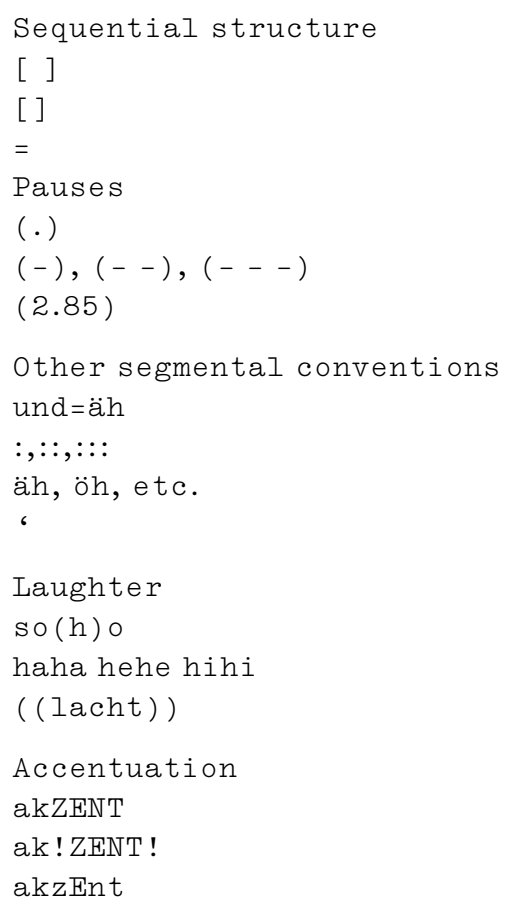

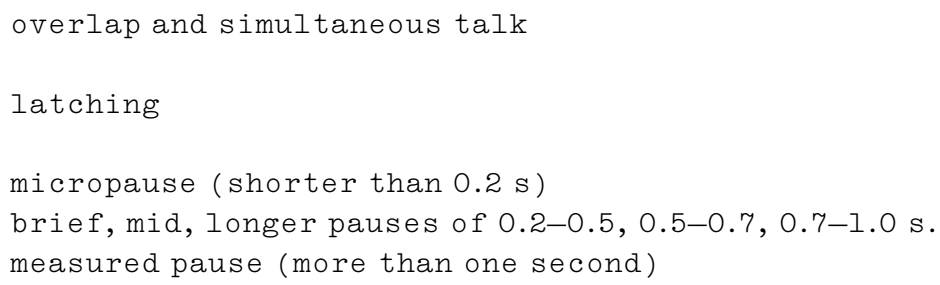

\footnotetext{
7 See Davidson (1977) for a lucid account of why presumptions of truth and coherence are necessary for a "radical interpretation" which, very much like CA, does not start with conventional meanings, but aims to induce meanings solely from a pattern of empirical linguistic events in a community of practice.
} 
Pitch at the end of units

?

$-$

;

Conspicuous pitch jumps

$\uparrow$

$\downarrow$

Changed register

$<<1>>$

$<<h>>$

Changes in loudness and speech rate

$<<\mathrm{f}>>$

$<<f f>>$

$<<\mathrm{p}>>$

$<<\mathrm{pp}>>$

$<<a 11>>$

$<<$ len $>>$

$<<$ cresc $>>$

$<<$ dim $>>$

$<<\operatorname{acc}>>$

$<<\operatorname{rall}>>$

Breathing

$. h, . h h, . h h h$

$\mathrm{h}, \mathrm{hh}, \mathrm{hhh}$

Other conventions

( (coughs $))$

$<<$ creaky voice $>>$

( )

(solche)

al ( $\mathrm{s}) 0$

(solche/welche)

$((\ldots))$ rising to high
rising to mid
level
falling to mid
falling to low

to higher pitch

to lower pitch

low register

high register

=forte, loud

=fortissimo, very loud

=piano, soft

=pianissimo, very soft

$=a l l e g r o$, fast

=lento, slow

=crescendo, continuously louder

=diminuendo, continuously softer

=accelerando, continuously faster

=rallentando, continuously slower

inbreath, according to duration

outbreath, according to duration

para- und extralinguistic activities and events commentaries regarding voice qualities with scope unintelligible according to duration

uncertain transcription

uncertain sounds or syllables

possible alternatives

omissions in the transcript

\section{References}

Anscombe, G.E., 1957. Intention. Blackwell, Oxford.

Atkinson, J.M., Heritage, J. (Eds.), 1984. Structures of Social Action. Studies in Conversation Analysis. Cambridge University Press, Cambridge.

Austin, J.L., 1962. How to Do Things with Words. Clarendon Press, Oxford.

Barth-Weingarten, D., 2008. Interactional linguistics. In: Antos, G., Ventola, E., Weber, T. (Eds.), Handbook of Applied Linguistics. Interpersonal

Communication, vol. 2. Walter de Gruyter, Berlin/New York, pp. 77-106.

Bergmann, J.R., 1985. Flüchtigkeit und methodische Fixierung sozialer Wirklichkeit: Aufzeichnungen als Daten interpretativen Soziologie. In: Bonß, W.,

Hartmann, H., 1985. Entzauberte Wissenschaft. Zur Relativität und Geltung soziologischer Forschung. Schwartz, Göttingen, pp. $299-320$.

Bilmes, J., 1985. 'Why that now?' Two kinds of conversational meaning. Discourse Processes 8, 319-355.

Cicourel, A.V., 1970. Methode und Messung in der Soziologie. Suhrkamp Verlag, Frankfurt a.M.

Clark, H.H., 1992. Areas of Language Use. University of Chicago Press, Chicago. 
Clark, H.H., 1996. Using Language. Cambridge University Press, Cambridge.

Clark, H.H., 1997. Dogmas of understanding. Discourse Processes 23, 567-598.

Consten, M., Knees, M., Schwarz-Friesel, M., 2009. Complex anaphors. The impact of ontology, context and conceptual knowledge. In: Zlatev, J., Johansson

Falck, M., Lundmark, C., Andrén, M. (Eds.), Studies in Language and Cognition. Cambridge Scholars Publishing, Newcastle, pp. $285-302$.

Coulter, J., 1989. Mind in Action. Polity Press, Cambridge, England.

Coulter, J., 2006. Language without mind. In: te Molder, H., Potter, J. (Eds.), Conversation and Cognition. Cambridge University Press, Cambridge, pp. 79-92.

Couper-Kuhlen, E., Selting, M. (Eds.), 2001. Studies in Interactional Linguistics. John Benjamins, Amsterdam/Philadelphia.

Davidson, D., 1973. Radical interpretation. Dialectica 27, 314-328.

Deppermann, A., 1997. Glaubwürdigkeit im Konflikt. Rhetorische Techniken in Streitgesprächen: Prozessanalysen von Streitgesprächen. Peter Lang Verlag, Frankfurt a.M.

Deppermann, A., 2000. Ethnographische Gesprächsanalyse: Zu Nutzen und Notwendigkeit von Ethnographie für die Konversationsanalyse. Gesprächsforschung. Online-Zeitschrift zur verbalen Interaktion 1, 96-124. <http://www.gespraechsforschung-ozs.de/heft2000/heft2000.htm>.

Deppermann, A., 2005. Conversational interpretation of lexical items and conversational contrasting. In: Hakulinen, A., Selting, M. (Eds.), Syntax and Lexis in Conversation: Studies on the Use of Linguistic Resources in Talk-in-Interaction. John Benjamins, Amsterdam/Philadelphia, pp. $289-317$.

Deppermann, A., 2008. Verstehen im Gespräch. In: Kämper, H., Eichinger, L.M. (Eds.), Sprache - Kognition - Kultur. Sprache zwischen mentaler Struktur und kultureller Prägung. Walter de Gruyter, Berlin/New York, pp. 225-261.

Deppermann, A., 2011a. Constructions vs. lexical items as sources of complex meanings. A comparative study of constructions with German verstehen. In: Auer, Peter, Pfänder, Stefan (Eds.), Emergent Constructions. Mouton de Gruyter, Berlin, pp. 88-126.

Deppermann, A., 2011b. Notionalization: The Transformation of Descriptions into Categorizations. Human Studies, 34 (2), $155-181$.

Deppermann, A., Schmitt, R., 2009. Verstehensdokumentation: Zur Phänomenologie von Verstehen in der Interaktion. Deutsche Sprache 3 (08), $220-245$.

Deppermann, A., Schütte, W., 2008. Data and transcription. In: Antos, G., Ventola, E., Weber, T. (Eds.), Handbook of Interpersonal Communication. Walter de Gruyter, Berlin/New York, pp. 179-213.

Drew, P., 1995. Interaction sequences and anticipatory interactional planning. In: Goody, E. (Ed.), Social Intelligence and Interaction. Expressions and Implications of the Social Bias in Human Intelligence. Cambridge University Press, Cambridge, pp. 111-138.

Drew, P., 2003. Comparative analysis of talk-in-interaction in different institutional settings. In: Glenn, Ph.J., LeBaron, C.D., Mandelbaum, J. (Eds.), Studies in Language and Social Interaction. Lawrence Erlbaum, Mahwah, NJ, pp. 293-308.

Drew, P., 2006. Is confusion a state of mind? In: te Molder, H., Potter, J. (Eds.), Conversation and Cognition. Cambridge University Press, Cambridge, pp. 161183.

Drew, P., Raymond, G., Weinberg, D. (Eds.), 2006. Talk and Interaction in Social Research Methods. Sage, London.

Edwards, D., 1997. Discourse and Cognition. Sage, London.

Edwards, D., Potter, J., 1992. Discursive Psychology. Sage, London.

Edwards, D., Potter, J., 2006. Discursive psychology, mental states and descriptions. In: te Molder, H., Potter, J. (Eds.), Conversation and Cognition. Cambridge University Press, Cambridge, pp. 241-259.

Garfinkel, H., 1967. Studies in Ethnomethodology. Prentice-Hall, Englewood Cliffs, NJ.

Geertz, C., 1973. The Interpretation of Cultures. Basic Books, New York.

Gibbs, R.W., 1999. Intentions in the Experience of Meaning. Cambridge University Press, Cambridge.

Graesser, A.C., 2006. Views from a cognitive scientist: cognitive representations underlying discourse are sometimes social. Discourse Studies 8, 59-66.

Grice, H.P., 1975. Logic and conversation. In: Cole, P.M., Jerry, L. (Eds.), Syntax and Semantics, Speech Acts, vol. 3. Academic Press, New York, pp. 41-58.

Grosz, B., Sidner, C.L., 1990. Plans for discourse. In: Cohen, P.R., Morgan, J., Pollack, M.E. (Eds.), Intentions in Communication. MIT Press, Cambridge, pp. 417440.

Günthner, S., 1996. The prosodic contextualization of moral work. An analysis of reproaches in why-formats. In: Couper-Kuhlen, E., Selting, M. (Eds.), Prosody in Conversation: Interactional Studies. Cambridge University Press, Cambridge, pp. 271-302.

Heritage, J., 1984a. A change-of-state token and aspects of its sequential placement. In: Atkinson, J.M., Heritage, J. (Eds.), Structures of Social Action. Studies in Conversation Analysis. Cambridge University Press, Cambridge, pp. 299-345.

Heritage, J., 1984b. Garfinkel and Ethnomethodology. Polity Press, Oxford.

Heritage, J., 1991. Intention, meaning and strategy. Observations on constraints on interaction analysis. Research on Language and Social Interaction 24, $311-332$.

Heritage, J., 1999. CA at century's end: practices of talk-in-interaction, their distributions and their outcomes. Research on Language and Social Interaction $32(1-2), 69-76$.

Heritage, J., 2006. Cognition in discourse. In: te Molder, H., Potter, J. (Eds.), Conversation and Cognition. Cambridge University Press, Cambridge, pp. 184202.

Heritage, J., Raymond, G., 2005. The terms of agreement. Indexing epistemic authority and subordination in talk-in-interaction. Social Psychology Quarterly $68,15-38$.

Heritage, J., Watson, R., 1979. Formulations as conversational objects. In: Psathas, G. (Ed.), Everyday Language. Studies in Ethnomethodology. Irvington, New York, pp. 123-162.

Hobbs, J.R., 2004. Abduction in natural language understanding. In: Horn, L., Ward, G. (Eds.), Handbook of Pragmatics. Blackwell, Oxford, pp. 724-741.

Hopper, R., 2006. A cognitive agnostic in conversation analysis. When do strategies affect spoken interaction? In: te Molder, H., Potter, J. (Eds.), Conversation and Cognition. Cambridge University Press, Cambridge, pp. 134-158.

Kintsch, W., 1998. Comprehension. A Paradigm for Cognition. Cambridge University Press, Cambridge.

Lakoff, G., 1987. Women, fire and dangerous things. What categories reveal about the mind. University of Chicago Press, Chicago.

Lakoff, G., Johnson, M., 1980. Metaphors We Live By. University of Chicago Press, Chicago.

Levinson, S.C., 1995. Interactional biases in human thinking. In: Goody, E.N. (Ed.), Social Intelligence and Interaction. Cambridge University Press, Cambridge, pp. 221-260.

Levinson, S.C., 2006. On the human “interaction engine”. In: Enfield, N.C., Levinson, S.C. (Eds.), Roots of Human Sociality: Culture. Cognition and Interaction. Berg, Oxford, pp. 39-69.

Linell, P., 2009. Rethinking Language, Mind, and World Dialogically. Information Age Publishing, Charlotte NC.

Mazeland, H., Huiskes, M., 2001. Dutch “but” as a sequential conjunction. Its use as a resumption marker. In: Couper-Kuhlen, E., Selting, M. (Eds.), 2001. Studies in Interactional Linguistics. John Benjamins, Amsterdam/Philadelphia, pp.141-169.

Norris, S., 2004. Analyzing Multimodal Interaction: A Methodological Framework. Routledge, London/New York.

Parsons, T., 1951. The Social System. Free Press, Glencoe, IL.

Pickering, M.J., Garrod, S., 2004. Toward a mechanistic psychology of dialogue. Behavioral and Brain Sciences 27 (2), 169-190.

Pomerantz, A., 1991. Mental concepts in the analysis of social action. Research on Language and Social Interaction 24, 299-310.

Potter, J., 1997. Discourse analysis as a way of analysing naturally occurring talk. In: Silverman, D. (Ed.), Qualitative Research. Theory, Method and Practice. Sage, London.

Potter, J., 1998. Cognition as context (whose cognition?). Research on Language and Social Interaction 31, 29-44.

Potter, J., 2006. Cognition and conversation. Discourse Studies 8, 131-140.

Potter, J., te Molder, H., 2006. Talking cognition: mapping and making the terrain. In: te Molder, H., Potter, J. (Eds.), Conversation and Cognition. Cambridge University Press, Cambridge, pp. 1-54.

Potter, J., Wetherell, M., 1987. Discourse and Social Psychology: Beyond Attitudes and Behaviour. Sage, London. 
Potter, J., Edwards, D., Wetherell, M., 1993. A model of discourse in action. American Behavioral Scientist 36 (3), $383-401$.

Psathas, G., 1995. Conversation Analysis. The Study of Talk-in-Interaction. Sage, London/New Delhi.

Quine, W.V.O., 1960. Word and Object. MIT Press, Cambridge.

Ryle, G., 1949. The Concept of Mind. Hutchinson's University Library, London.

Sacks, H., 1984. Notes on methodology. In: Atkinson, J.M., Heritage, J. (Eds.), Structures of Social Action. Studies in Conversation Analysis. Cambridge University Press, Cambridge, pp. 21-27.

Sacks, H., 1985. The inference making machine. In: van Dijk, T.A. (Ed.), Handbook of Discourse Analysis, vol. III. Academic, London, pp. $13-23$.

Sacks, H., 1992. In: Jefferson, G. (Ed.), Lectures on Conversation, vol. I \& II. Blackwell, Oxford.

Sanders, R.E., 2006. Validating 'observations' in discourse studies: a methodological reason for attention to cognition. In: te Molder, H., Potter, J. (Eds.), Conversation and Cognition. Cambridge University Press, Cambridge, pp. 57-78.

Schaeffer, N.C., Maynard, D.W., 2006. From paradigm to prototype and back again. Interactive aspects of cognitive processing in standardized survey interviews. In: te Molder, H., Potter, J. (Eds.), Conversation and Cognition. Cambridge University Press, Cambridge, pp. 114-133.

Schegloff, E.A., 1992. Repair after next turn. The last structurally provided defence of intersubjectivity in conversation. American Journal of Sociology 97 (5), $1295-1345$.

Schegloff, E.A., 1993. Reflections on quantification in the study of conversation. Research on Language and Social Interaction $26,99-128$.

Schegloff, E.A., 1995. Discourse as an interactional achievement III. The omnirelevance of action. Research on Language and Social Interaction 28, 185-211.

Schleiermacher, F.D.E., 1838 [1977]. Hermeneutik und Kritik. Mit einem Anhang sprachphilosophischer Texte Schleiermachers. Hrsg. und eingeleitet von Manfred Frank. Suhrkamp Verlag, Frankfurt a.M.

Schmitt, R., Deppermann, A., 2007. Monitoring und Koordination als Voraussetzungen der multimodalen Konstitution von Interaktionsräumen. In: Schmitt, R. (Ed.), Koordination. Analysen zur multimodalen Interaktion. Gunter Narr Verlag, Tübingen, pp. 95-128.

Scholz, O.R., 2001. Verstehen und Rationalität. Untersuchungen zu den Grundlagen von Hermeneutik und Sprachphilosophie. Klostermann, Frankfurt a.M.

Searle, J.R., 1969. Speech Acts. An Essay in the Philosophy of Language. Cambridge University Press, Cambridge.

Searle, J.R., 1983. Intentionality. An Essay in the Philosophy of Mind. Cambridge University Press, Cambridge.

Selting, M., Barth-Weingarten, D., Bergmann, J., Bergmann, P., Birkner, K., Couper-Kuhlen, E., Deppermann, A., Gilles, P., Günthner, S., Hartung, M., Kern, F.,

Mertzlufft, C., Meyer, C., Morek, M., Oberzaucher, F., Peters, J., Quasthoff, U., Schütte, W., Stukenbrock, A., Uhmann, S., 2011. A system for transcribing talk-in-interaction: GAT 2 translated and adapted for English by Elizabeth Couper-Kuhlen and Dagmar Barth-Weingarten. Gesprächsforschung 12, 1-51, <http://www.gespraechsforschung-ozs.de/heft2011/px-gat2-englisch.pdf>.

Sidnell, J., 2005. Talk and Practical Epistemology: The Social Life of Knowledge in a Caribbean Community. John Benjamins, Amsterdam/Philadelphia.

Suchman, L., 1987. Plans and Situated Actions. The Problem of Human-Machine-Communication. Cambridge University Press, Cambridge.

te Molder, H., Potter, J. (Eds.), 2006. Conversation and Cognition. Cambridge University Press, Cambridge.

Wittgenstein, L., 1953. Philosophical Investigations (Translated by G.E.M. Anscombe). Blackwell, Oxford.

Wolff, S., Müller, H., 1997. Kompetente Skepsis. Eine konversationsanalytische Untersuchung zur Glaubwürdigkeit in Strafverfahren. Westdeutscher Verlag, Opladen.

Wooffitt, R., 2005. Conversation analysis and discourse analysis. Sage, London. 